\title{
Electrophysiological and Morphological Properties of Layers V-VI Principal Pyramidal Cells in Rat Prefrontal Cortex In Vitro
}

\author{
Charles R. Yang, ${ }^{1,2}$ Jeremy K. Seamans, ${ }^{1}$ and Natalia Gorelova1 \\ Departments of 1 Psychology, and ${ }^{2} P$ sychiatry, University of British Columbia, Vancouver, British Columbia, \\ Canada V6T $1 Z 4$
}

This study examined the electrophysiological and morphological characteristics of layers $\mathrm{V}-\mathrm{V}$ l pyramidal prefrontal cortex (PFC) neurons. In vitro intracellular recordings coupled with biocytin injections that preserved some of the PFC efferents to the nucleus accumbens (NAc) were made in brain slices. Four principal pyramidal cell types were identified and classified as regular spiking (RS) (19\%), intrinsic bursting (IB) $(64 \%)$, repetitive oscillatory bursting (ROB) $(13 \%)$, and intermediate (IM) (4\%) types. All PFC cells exhibited either subthreshold oscillation in membrane voltage or pacemaker-like rhythmic firing. IB neurons were demonstrated electrophysiologically and cytochemically to be PFC $\rightarrow$ NAc neurons.

In all IB and some RS neurons, a tetrodotoxin-sensitive, slowly inactivating $\mathrm{Na}^{+}$current and a transient $\mathrm{Ni}^{2+}$-sensitive, low-threshold $\mathrm{Ca}^{2+}$ current mediated subthreshold inward rectification. During sustained membrane depolarization, the $\mathrm{Na}^{+}$ current was opposed by a 4-aminopyridine-sensitive, outwardly rectifying, slowly inactivating $\mathrm{K}^{+}$current. Together, these three currents controlled the firing threshold of the PFC neurons.

All IB and ROB cells also had postspike $\mathrm{Ca}^{2+}$-mediated depolarizing afterpotentials, postburst $\mathrm{Ca}^{2+}$-dependent afterhyperpolarizations, and low- and high-threshold $\mathrm{Ca}^{2+}$ spikes. In addition, ROB cells had a hyperpolarizing "sag" mediated by the cationic conductance, $I_{\mathrm{h}}$. IB and ROB neurons had extensive dendritic trees and radially ascending or tangentially projecting axon collaterals. RS and IM cells had comparatively simpler morphological profiles. These electrophysiological and morphological properties of the four principal pyramidal PFC cell types have provided valuable details for understanding further how PFC processes input and transmit outputs to regions such as the NAc.

Key words: prefrontal cortex; electrophysiology; slow or persistent sodium; slow potassium; oscillation; morphology; calcium spikes
The mammlian prefrontal cortex (PFC) encompasses a broad arca that is innervated reciprocally by major projections emanating from the mediodorsal thalamus (Groenewegen, 1988; Uylings and van Eden, 1990). In rats, the prelimbic, infralimbic, and ventral anterior cingulate cortex represent the major subdivisions of the PFC (Groenewegen, 1988). Based on their patterns of neural connectivity, these subregions are thought to be related functionally to Walker's areas $24,25,32$, and 46 in the primate (Kolb, 1984; Uylings and van Eden, 1990; Condé el al., 1995).

Functional studies in primates emphasize that the PFC influences the organization and planning of purposive movements via its integration into the neural network of the basal ganglia. The firing of some PFC neurons increases throughout the delay period of a delayed-response task when information must be "held" momentarily and used subsequently to guide correct responses

Received June 7, 1995; revised Oct. 24, 1995; accepted Nov. 22, 1995.

Research funding to this study was awarded to C.R.Y. by the British Colurnbia Health Research Foundation (BCHRF) and the Medical Research Council of Canada. C.R.Y. is a BCHRF scholar. J.K.S. is a recipient of the University of British Columbia Graduatc Fellowship. We thank Drs. Anthony Phillips, Charles Blaha, Ariane Coury, and John Church, as well as Mr. Fred LePiane and Keith Waldron, for their resourceful help. We are grateful to Drs. H. C. Fibiger and S. R. Vincent of the Kinsman Neurological Institute, Department of Psychiatry, for the use of the darkroom and microscope facilities, and to Dr. Ken Baimbridge for advice on fluorescence photomicroscopy. We also thank Dr. Michael Hermes for providing us with the detailed procedures for the processing of intracellular biocytin-stained neurons in unsectioned thick brain slices.

Correspondence should be addressed to Charles R. Yang, Department of Psychology, University of British Columbia, 2136 West Mall, Vancouver, British Columbia, Canada V6T 124.

Copyright $\mathcal{C} 1996$ Society for Neuroscience $\quad 0270-6474 / 96 / 161904-18 \$ 05.00 / 0$
(Fuster, 1995; Goldman-Rakic, 1995a). In our recent behavioral studics, we have shown that the rat prelimbic cortex is involved in the generation and revision of planned foraging behaviors on a spatially cued eight-arm radial maze (Seamans et al., 1995). Of particular importance for the execution of planned responses are the pyramidal output neurons, which reside in the deep layers V-VI of the PFC and project to the dorsal and ventral striatum (Sesack et al., 1989; Groenewegen et al., 1990; Berendse et al., 1992; Brog et al., 1993; Gorelova et al., 1994). These corticostriatal neurons may play a critical role in translating plans generated by the PFC into temporally scquenced actions (Mogenson et al., 1993; Seamans and Phillips, 1994; Goldman-Rakic, 1995a). However, the major intrinsic membrane properties that regulate the excitability of PFC neurons, and corticostriatal neurons that project to the nucleus accumbens (NAc) remained undefined.

Electrophysiological studies combined with morphological identification of the recorded neurons in diverse cortical areas have revealed at least three types of pyramidal neocortical neurons within the deep layers (Connors et al., 1982; Connors and Gutnick, 1990; Larkman and Mason, 1990; Silva et al., 1991; McCormick, 1992; van Brederode and Snyder, 1992; Kawaguchi, 1993; Kang and Kayano, 1994). These cell types, called "regular spiking" (RS), "intrinsic bursting" (IB), and repetitive oscillatory bursting" (ROB), possess a number of ionic conductances that determine neuronal excitability. These intrinsic membrane properties of neurons are involved critically in the integration of synaptic inputs into spike train output (Llinas, 1986; Schwindt, 1992). Thus, we characterized the major ionic conductances that 


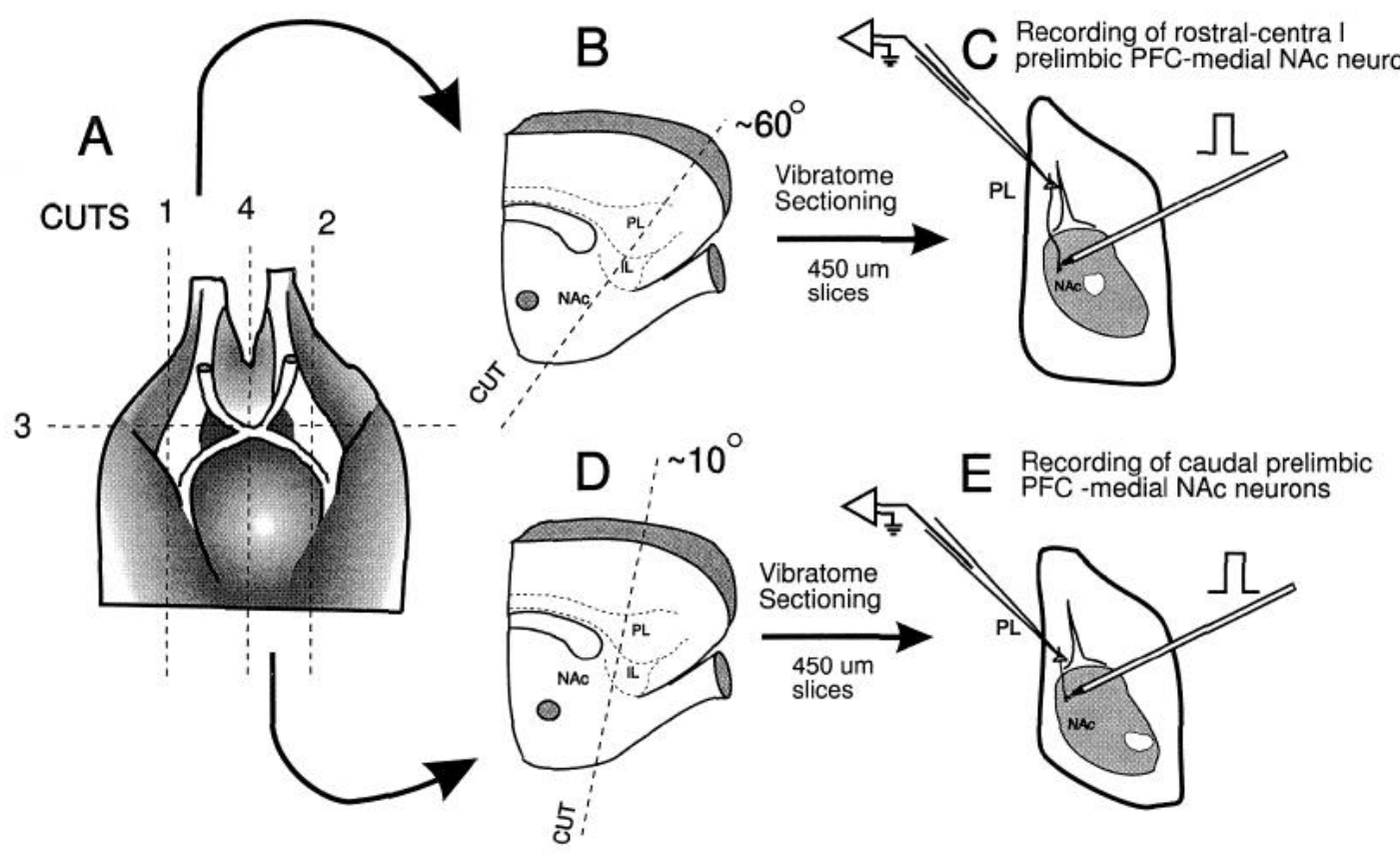

Figure 1. Procedures for the preparation of brain slices that preserved some of the PFC $\rightarrow$ NAc projections. After removal of the whole brain from the skull of the rat, the brain was cooled down rapidly for $1 \mathrm{~min}$ at $4^{\circ} \mathrm{C}$ in ACSF. $A$. Four cuts were made from the ventral surface of the cooled rat brain (1-4, dotted line ). $B$, An oblique cut $\sim 60^{\circ}$ to the horizontal plane was made from half of the trimmed brain tissue. This cutting angle preserves central prelimbic neurons that project to the NAc. $C$, Slices $(400-450 \mu \mathrm{m})$ were cut using a vibratome. Stimulation electrodes were placed on the medial and/or the lateral part of the NAc to activate antidromically intracellularly recorded prelimbic neurons that project to the NAc. $D$, Alternatively, an oblique cut $\sim 10^{\circ}$ to the horizontal plane was made from the other half of the trimmed brain tissue. $E$, Slices cut preserved the caudal prelimbic and dorsal infralimbic PFC neurons that project to the NAc. The angles of cutting were derived from the routes with which the prelimbic $\rightarrow$ NAc fibers projected as investigated using anterograde tracer biotin dextranamine in our neural tract tracing studies (Gorelova et al., 1994).

determine the intrinsic membrane properties and membrane excitability of PFC neurons to attain insight into how PFC neurons integrate incoming signals to produce an output. The companion paper (this issue) examines how dopamine modulates some of the ionic conductances described in the present paper. Preliminary findings have been communicated previously in abstract form (Yang and Seamans, 1994).

\section{MATERIALS AND METHODS}

Young adult male Sprague-Dawley rats ( $80-100$ gm, University of British Columbia colony) were used in this study. After decapitation, the brain was dissected rapidly and immersed for $1 \mathrm{~min}$ in cold $\left(4^{\circ} \mathrm{C}\right)$ oxygenated (with $95 \% \mathrm{O}_{2} / 5 \% \mathrm{CO}_{2}$ ) artificial CSF (ACSF) containing (in $\mathrm{mm}$ ): $\mathrm{NaCl}$ $126, \mathrm{KCl} 3, \mathrm{NaHCO}_{3} 26, \mathrm{MgCl}_{2} 1.3, \mathrm{CaCl}_{2} 2.3$, and glucose 10 . The lateral halves of the brain were removed from each hemisphere. A coronal cut was made just caudal to the optic chiasma, isolating the forebrain. The two hemispheres were divided further by a midline parasaggittal cut. We have demonstrated recently that PFC neurons project in an oblique direction to the NAc (Gorelova et al., 1994). Thus, to preserve a portion of the $\mathrm{PFC} \rightarrow \mathrm{NAc}$ pathway, oblique cuts from each half of the forebrain block were made at about $60^{\circ}$ or $10^{\circ}$ to the horizontal plane (Fig. 1). Slices prepared from a saggital cut failed to preserve most of the apical dendrites of the deep layers V-VI pyramidal neurons, and slices prepared from a coronal cut failed to preserve most of the axonal projections from the PFC to the NAc. (Gorelova et al,, 1994).

Each tissue block was glued onto the cutting stage of a vibratome (Vibraslice) by cyanoacrylic-based glue and anchored by a block of agar ( $4 \%$ in saline). Oblique slices $(450 \mu \mathrm{M})$ that retained the PFC and the NAc were cut from each hemisphere using the vibratome. The slices were incubated in oxygenated ACSF for $1 \mathrm{hr}$ at room temperature before electrophysiological recordings began.

Recordings and stimulations. In the recording chamber (Medical System Corps., Greenvale, NY), the slice was held by a nylon net and perfused by gravity-fed ACSF (maintained at $34^{\circ} \mathrm{C}$ ) at a rate of 3-4 ml/min. Standard sharp electrode intracellular recordings were made using thick-walled borosilicate micropipettes $(1.2 \mathrm{~mm}$ outer diameter, $0.6 \mathrm{~mm}$ inner diameter) (Sutter Instrument, Novato, CA), which were prepared on a hori- zontal micropipette puller (Flaming-Brown P-87, Sutter Instrument, Novato, CA). Microelectrodes were filled with $1.5 \%$ biocytin (Sigma, St. Louis, MO) in $3 \mathrm{M}$ potassium acetate, $3 \mathrm{~m}$ potassium acetate alone, or 3 $\mathrm{M}$ cesium acetate. The electrodes had a final resistance between 90 and $130 \mathrm{M} \Omega$. The microelectrode was connected to the headstage of an Axoclamp-2B amplifier (Axon Instruments, Foster City, CA) with $\mathrm{Ag}$ / $\mathrm{AgCl}$ wire. Changes in junctional potential at the indifferent electrode were minimized by connecting the $\mathrm{Ag} / \mathrm{AgCl}$ reference electrode to an agar bridge (a block of $4 \%$ agar in saline at the end of a glass pipette that is filled with $3 \mathrm{M} \mathrm{KCl}$ solution). Bridge balance was monitored continuously on the oscilloscope (Tetronix D13) to subtract the voltage drop across the electrode resistance. Capacitance transients were also compensated optimally. The recorded voltage signals were amplified in current-clamp bridge mode, digitized by a Digidata $2000 \mathrm{~A} / \mathrm{D}$ board (Axon Instruments), and sampled on-line using a PC-based computer. The captured data were analyzed off-line using pClamp software (Version 5.5, Axon Instruments).

The resting membrane potential was estimated by taking the difference between the $V_{\mathrm{m}}$ reading when the electrode was inside the cell (with no DC current injected) and the $V_{\mathrm{m}}$ reading when the electrode was outside the cell at the end of the recording period. Neuronal input resistance $\left(R_{\mathrm{N}}\right)$ was determined by dividing the difference in membrane voltage in response to a hyperpolarizing current pulse that caused a voltage deflection $\sim 10 \mathrm{mV}$ by the amount of current injected. The membrane time constant $(\tau)$ was fitted from the onset of the response to a hyperpolarizing pulse to the beginning of the steady-state condition. Although some cells showed clear indications of more than one fast equalizing time constant, only the final single slow-time constant fitting is reported in this study.

Electrophysiological identification of different PFC cell types. Two separate protocols were used to induce distinct firing patterns that identified each type of PFC neuron: (1) fixed-amplitude depolarizing pulses (70$200 \mathrm{msec}$ ) were delivered intracellularly as the steady-state $V_{\mathrm{m}}$ was adjusted to different voltages by continuous DC current injection; and (2) progressive increases in the amplitude of the depolarizing current pulses were delivered intracellularly as the steady-state $V_{\mathrm{m}}$ was held constant.

Drugs. All drugs were bath-applied by gravity. Complete exchange of the bathing solution took $\sim 2$ min. 4-aminopyridine (4-AP), tetraethylammonium hydrochloride (TEA), and tetrodotoxin (TTX) were obtained 
from Research Biochemical or Sigma. In experiments in which $\mathrm{Co}^{2+}$ was used, $\mathrm{NaHCO}_{3}$ was replaced with Tris (base), and the $\mathrm{pH}$ of the solution was adjusted to 7.4 after oxygenation to prevent divalent cation precipitation.

Biocytin staining in unsectioned brain slices. To trace the entire somadendritic profile of recorded PFC neurons, biocytin was injected iontophoretically during intracellular recordings either continuously or by means of anodal current pulses $(200 \mathrm{msec}, 100-300 \mathrm{pA}, 1 \mathrm{~Hz})$ for at least $20 \mathrm{~min}$. After the recording sessions, brain slices were fixed in $4 \%$

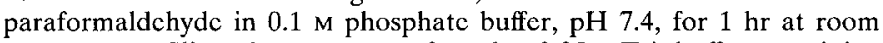
temperature. Slices then were transferred to $0.05 \mathrm{M}$ Tris buffer containing $1 \%$ Triton $\mathrm{X}-100$ and stored at $4^{\circ} \mathrm{C}$ for $48 \mathrm{hr}$. After this period, the endogenous hydrogen peroxidase activity was then neutralized with $30 \%$ hydrogen peroxide in methanol (1:60 dilution) for $30 \mathrm{~min}$. After washing with Tris-Triton, the tissue was incubated with a streptavadin-horseradish peroxidase complex (1:200 dilution) containing 3\% fish gelatin (Sig$\mathrm{ma}$ ) in Tris-Triton for $2 \mathrm{hr}$ at room temperature. After washing with Tris buffer, the tissue was incubated with diaminobenzidine $(1 \mathrm{mg})$ and hydrogen peroxide for $5 \mathrm{~min}$. Finally, the reaction was stopped by washing in $0.1 \mathrm{M}$ PBS. After dehydration of the slices through a series of alcohol, the tissue was cleared in methylsalicylate and the entire $400-450 \mu \mathrm{m}$ slice was mounted for examination using light microscopy. Camera lucida drawings and photographs of the entire stained neurons were made. The exact locations of thesc neurons wcre verificd with reference to identical sections counterstained with cresyl violet.

Identification of PFC neurons that project to the NAc. PFC output neurons that project to the NAc were identified electrophysiologically and histochemically. First, electrical stimulation of the NAc was used to determine whether the impaled $\mathrm{PFC} \rightarrow \mathrm{NAc}$ neurons could be activated antidromically. Constant current electrical stimulation $(50-500 \mu \mathrm{A}, 0.2$ msec duration at $1 \mathrm{~Hz}$ ) was delivered through a concentric bipolar stimulating electrode (SNE-100, Rhodes Medical, Tujunga, CA) to the rostrolateral or the rostromedial portions of the NAc. Criteria for an antidromic response included (1) constant latency of the antidromic response at threshold current stimulation, (2) invariable latency with membrane hyperpolarization, (3) high-frequency following at $>100 \mathrm{~Hz}$, and (4) collision of the antidromic spike with an intracellularly evoked orthodromic spike when the interval between the spikes was less than twice the antidromic conduction time (Lipski, 1981).

Second, PFC neurons projecting to the NAc also were identified using the method of retrograde labeling with rhodamine-conjugated latex "beads" (Luma Fluor, New City, NY). Four to $8 \mathrm{~d}$ before electrophysiological experiments, animals ( 80 and $100 \mathrm{gr}$ ) were anesthetized with a mixture of ketamine $(50 \mathrm{mg} / \mathrm{kg}, \mathrm{i} . \mathrm{m}$.) and nembutal $(35 \mathrm{mg} / \mathrm{kg}$, i.p.).
Rhodamine beads $(0.3 \mu \mathrm{l})$ were microinjected into the NAc stereotaxically via a glass pipette (tip diameter $35-40 \mu \mathrm{M}$; anteroposterior, $9 \mathrm{~mm}$, lateromedial, $3 \mathrm{~mm}$ subtended at $20^{\circ}$, dorsoventral, $6.3-6.7 \mathrm{~mm}$; with the ear bar and the incisor bar set at $0 \mathrm{~mm}$ ) (Sherwood and Timiras, 1970). The tracer deposit in the NAc encompassed both the core and the shell regions of the NAc.

Six to $8 \mathrm{~d}$ after injection, $400 \mu \mathrm{m}$ brain slices were prepared for in vitro electrophysiological experiments in the manner described above. Once a PFC neuron was impaled, depolarizing pulses (100-200 msec, delivered at $1 \mathrm{~Hz}$ ) werc uscd to cject biocytin ( $1.5 \%$ in $3 \mathrm{M}$ potassium acctatc) intracellularly through the recording electrode. At the end of each electrophysiological experiment, the brain slices were fixed in $4 \%$ paraformaldehyde in $0.1 \mathrm{M}$ phosphate buffer for $1-1.5 \mathrm{hr}$, washed in $0.05 \mathrm{M}$ PBS, and put into $30 \%$ sucrose in $0.05 \mathrm{M}$ PBS for cryoprotection. Forty micrometer sections were cut and mounted on gelatin-coated slides. Slides then were incubated $2-3 \mathrm{hr}$ at room temperature with fluorescein isothiocyanate (FITC)-conjugated avidin (Vector Laboratories, Burlingame, CA). After washing in $0.05 \mathrm{M}$ PBS, the slides were covered with SlowFade mounting liquid (Molecular Probes, Eugene, OR) to prevent photobleaching. A fluorescence microscope with appropriate filters for FITS and rhodamine was used to identify neurons filled with biocytin and rhodamine beads. Photographs were taken using Kodak (Rochester, NY) T-Max or Ektachrome 800/1600 films (both rated at ASA 800).

\section{RESULTS}

Stable intracellular recordings (lasting $0.3-5 \mathrm{hr}$ ) were obtained from 99 neurons located in layers V-VI of the prelimbic and dorsal infralimbic regions of the PFC. Only PFC neurons with action potentials that overshot $0 \mathrm{mV}$ and resting membrane potentials greater than $-60 \mathrm{mV}$ were included in the data analysis. In this voltage range, there was a general lack of spontaneous firing in most PFC neurons recorded. One exception was the ROB neurons described below.

Four distinct groups of pyramidal neurons in layers V-VI of the PFC were classified based on their evoked firing pattern in response to intracellular depolarizing pulses and morphological profiles. They have been termed RS, IB, ROB, and intermediate (IM) cells.

\section{RS neuron (see Fig. 2)}

Nineteen PFC neurons (19\%) were classified as RS cells. These cells had a mean $V_{\mathrm{m}}$ of $-74.3 \pm 1.7 \mathrm{mV}$, a mean $R_{\mathrm{N}}$ of $105 \pm 15$
Figure 2. Electrophysiological characteristics of a typical RS PFC neuron. $A$, Voltage deflections in response to intracellular injection of a series of depolarizing and hyperpolarizing pulses (left) (200 msec, $20 \mathrm{pA}$ per step). Note the high resting membrane potential of -75 $\mathrm{mV}$, the linearity of the V-I plot between -70 and -95 and $\mathrm{mV}$ in this cell, and its slope resistance of $67 \mathrm{M} \Omega$ (right). $B$, Injection of a fixed depolarizing pulse $(100 \mathrm{pA})$ in each case as the $V_{\mathrm{m}}$ was held progressively toward more depolarized voltage range via continuous constant DC current injection (left to right). As the steady-state $V_{\mathrm{m}}$ was adjusted from -85 to $-50 \mathrm{mV}$, more action potentials with greater interspike intervals were elicited by the same depolarizing pulse. Each spike was repolarized rapidly by an fAHP, followed by a mAHP that lasted for tens of milliseconds. Note that on no occasion did this RS neuron fire in bursts. $C$, Membrane potential was held at $-75 \mathrm{mV}$ and the amplitude of the depolarizing pulses injected was increased progressively (left to right). Single spike with progressive spikefrequency adaptation as observed. Note again the absence of burst firing.

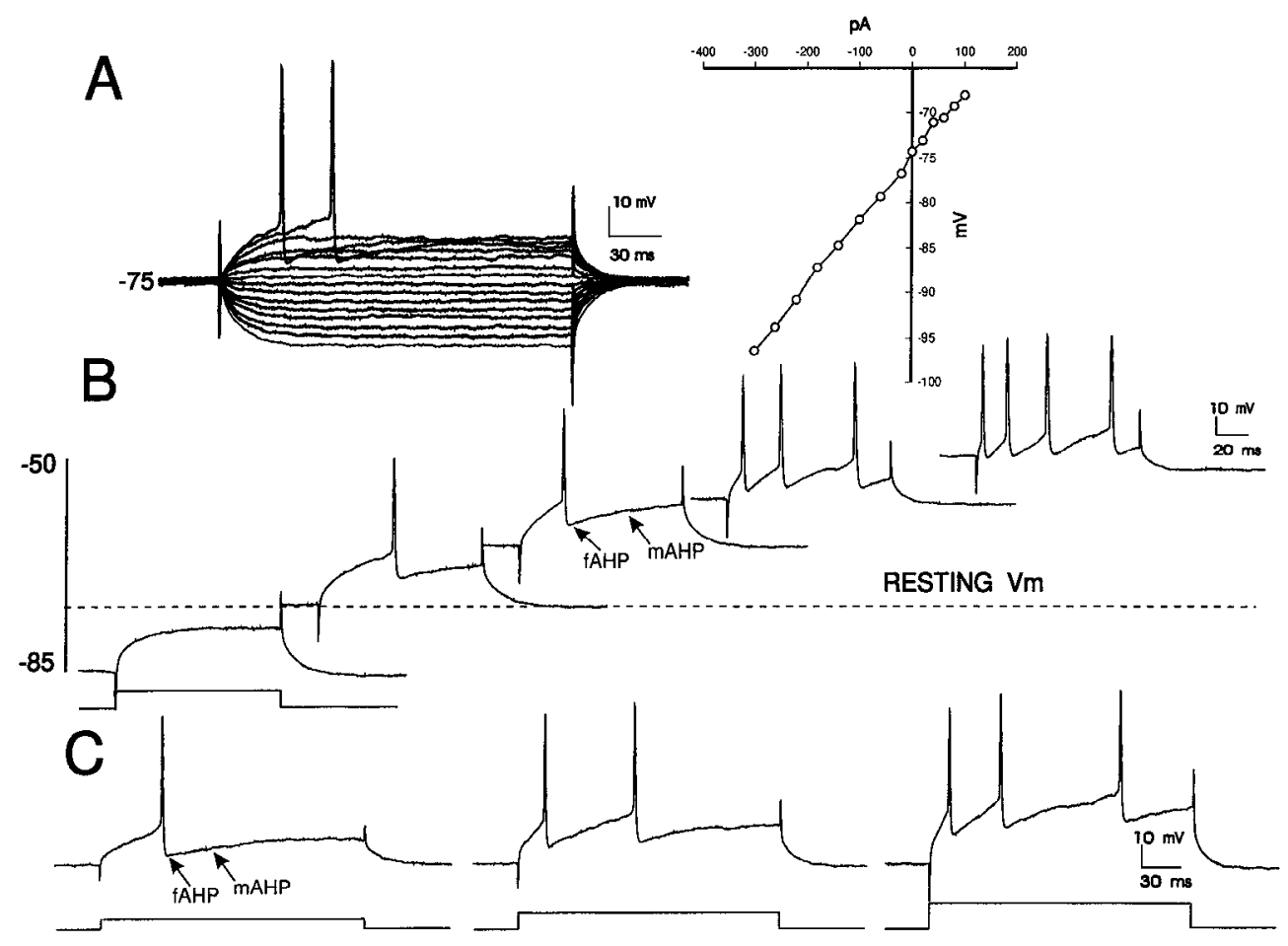


Table 1. A summary of the intrinsic membrane properties of the four principal pyramidal cell types in the deep layers $V$-VI of the PFC

\begin{tabular}{|c|c|c|c|c|c|}
\hline Cell types & Resting $V_{\mathrm{m}}(\mathrm{mV})$ & Spike threshold $(\mathrm{mV})$ & Time constant (msec) & Input resistance $(\mathrm{M} \Omega)$ & $n$ \\
\hline RS & $-74.3 \pm 1.7$ & $-51.6 \pm 1.9$ & $15 \pm 1.56$ & $105 \pm 15$ & 19 \\
\hline IB & $-71.8 \pm 1.24$ & $-51.8 \pm 1$ & $17.9 \pm 0.9$ & $109 \pm 8$ & 63 \\
\hline ROB & $-65 \pm 5$ & $-58 \pm 3$ & $12.3 \pm 0.8$ & $83 \pm 9.5$ & 13 \\
\hline IM & $-71.8 \pm 3.6$ & $-50.7 \pm 2$ & $16.5 \pm 2$ & $90 \pm 8$ & 4 \\
\hline
\end{tabular}

$\mathrm{M} \Omega$ (see Table 1), a mean firing threshold of $-51.6 \pm 2 \mathrm{mV}$, and a $\tau$ of $15 \pm 1.56 \mathrm{msec}$. The voltage-current relationship of a typical RS neuron was linear at membrane potentials between -70 and $-100 \mathrm{mV}$ (Fig. 2).

\section{Repetitive firing patterns}

When held at potentials more positive than resting $V_{\mathrm{m}}$, RS neurons typically fired a train of single spikes in response to an injection of a short duration (100 msec) suprathreshold depolarizing current pulse. Under no conditions were spike bursting complexes recorded in any of the RS PFC neurons. Each spike in the spike train repolarized rapidly beyond rest, yielding a welldefined 6-10 $\mathrm{mV}$ prolonged (tens of msec) postspike afterhyperpolarization (AHP). This long AHP was responsible for the progressively longer interspike interval between subsequent spikes. When the $V_{\mathrm{m}}$ was held gradually at more positive potentials, the same depolarizing pulse elicited more spikes with progressively increasing interspike intervals, i.e., there was an increase of spike frequency adaptation (Fig. 2). When the $V_{\mathrm{m}}$ was held at a fixed membrane potential, progressive increases in the amplitude of the injected depolarizing pulses also elicited a train of single spikes with marked spike frequency adaptation.

\section{Subthreshold membrane oscillation}

RS neurons displayed rhythmic membrane voltage oscillations at potentials above rest but below firing threshold (Fig. 3) (7/7 tested). This type of oscillation was observed after sustained depolarization via injection of a long (1-3 sec) depolarizing pulse. At potentials near firing threshold, the amplitude of the oscillations varied from 1 to $5 \mathrm{mV}$ in a voltage-dependent manner and often were mixed with spikes (Fig. $3 A, B$ ). In contrast, the oscillation frequency was not voltage-dependent but was stable within a narrow range (5-12 Hz) (Fig. $3 B$ ). The narrow-frequency membrane oscillation was blocked by bath application of TTX $(1 \mu \mathrm{M}$; $n=8$ ) (Fig. $3 C, D$ ) or intracellular injection of the lidocaine derivative $\mathrm{Na}^{+}$channel blocker QX314 $(n=5)$ (data not shown).

\section{Membrane anomalous rectification}

There was little or no anomalous inward rectification detected in either the hyperpolarized or the depolarized membrane voltage range after injection of $100 \mathrm{msec}$ pulses. As a result, $\mathrm{RS}$ cells had a fairly lincar current-voltage plot (sec Fig. $2 A$ ). Howcver, by injecting an incremental series of long (1-3 sec) sustained depolarizing pulses, a delayed membrane outward rectification was revealed (Figs. $3 B, 4 A$ ). This outward rectification counteracted
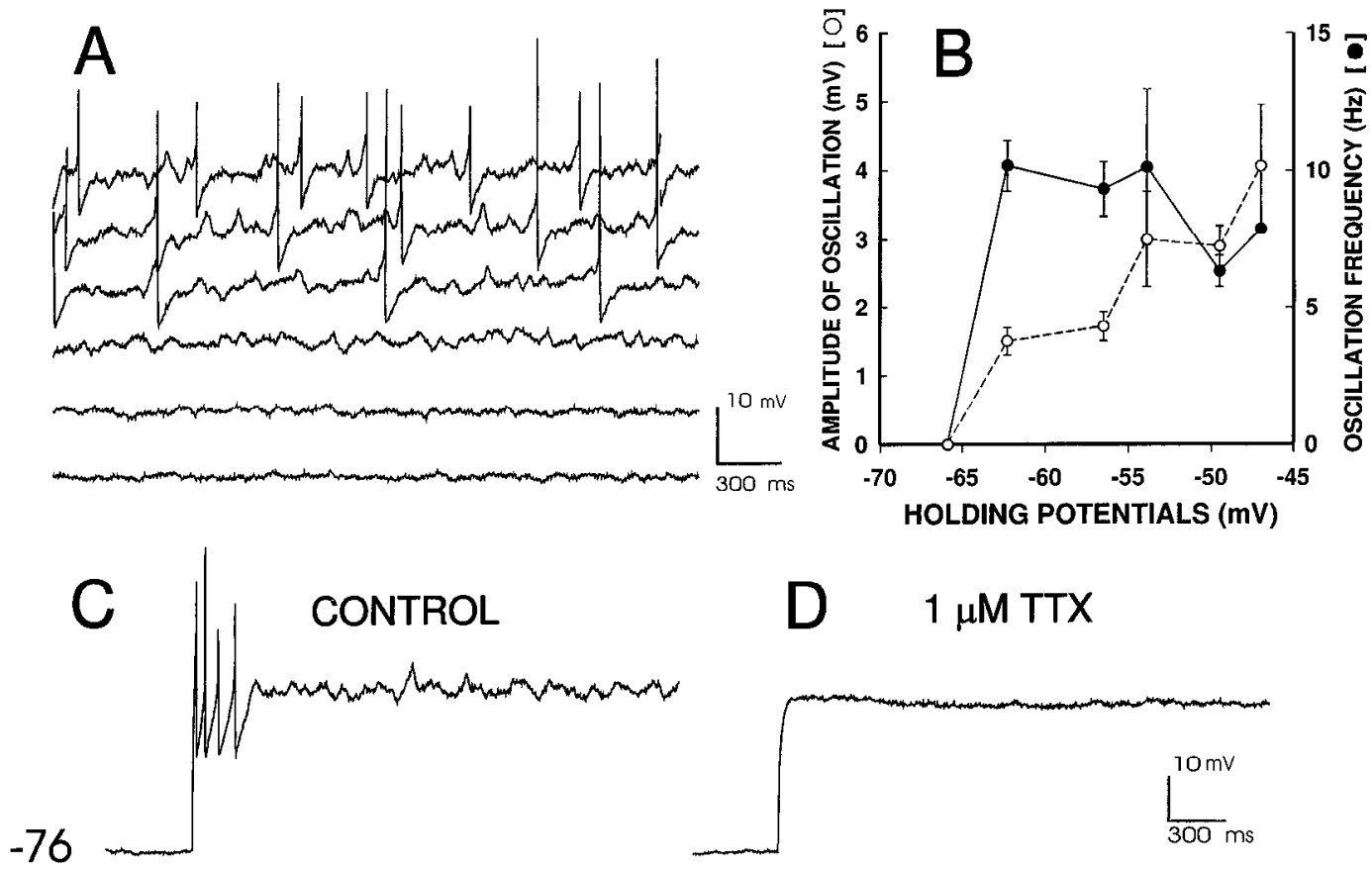

D $\quad 1 \mu \mathrm{M} T \mathrm{TX}$

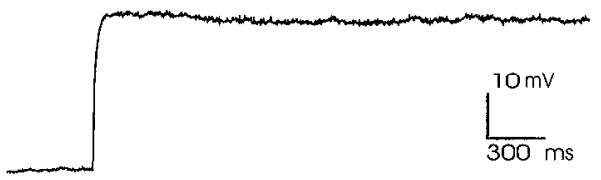

$400 \mathrm{pA}$

Figure 3. Voltage-dependent subthreshold membrane oscillation in RS neuron. $A$, Subthreshold membrane oscillation displayed an all-or-none onset characteristic. Note that all spikes are truncated. $B$, The oscillatory frequencies (filled circles) are restricted to a narrow-frequency band between 5 and $13 \mathrm{~Hz}$, but the amplitude of the oscillation increased with progressive membrane depolarizations (open circles). $C, D$, The subthreshold membrane oscillation during an injection of a sustained depolarizing pulse into this RS neuron was blocked by bath application of TTX (1 $\mu \mathrm{M})$. 


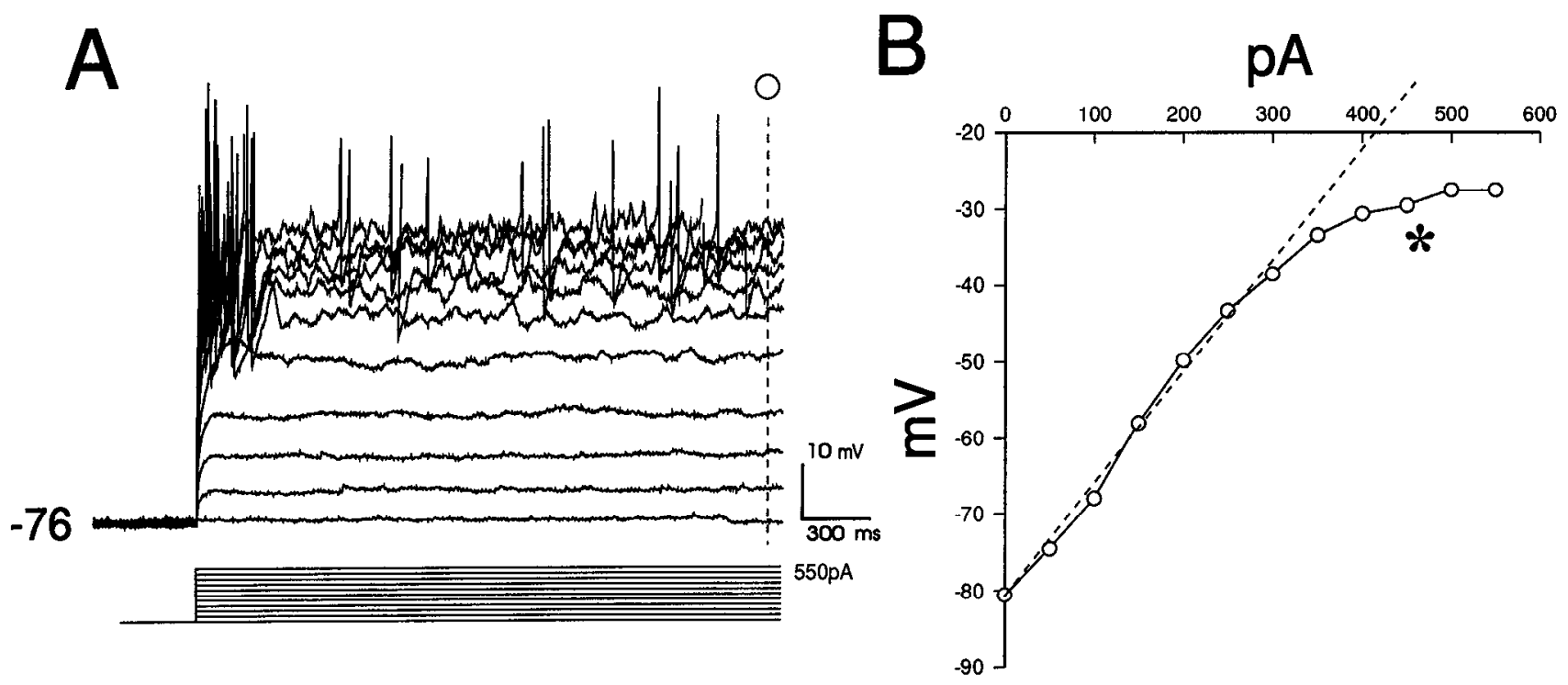

Figure 4. An outward rectification in the threshold voltage range of RS neurons. $A$, Sustained depolarizing pulses evoked from resting $V_{\mathrm{m}}$ ( $-76 \mathrm{mV}$ ), subthreshold membrane oscillations, and a membranc outward rectification. Spikes werc truncated. $B$, V-I plot from steady-state readings of the voltage deflections in response to a series of depolarizing current injections (open circles) showed marked outward rectification (asterisk) that was responsible for the downward bend of the V-I plot. The outward rectification began at $\simeq-43 \mathrm{mV}$ in this $\mathrm{RS}$ neuron.

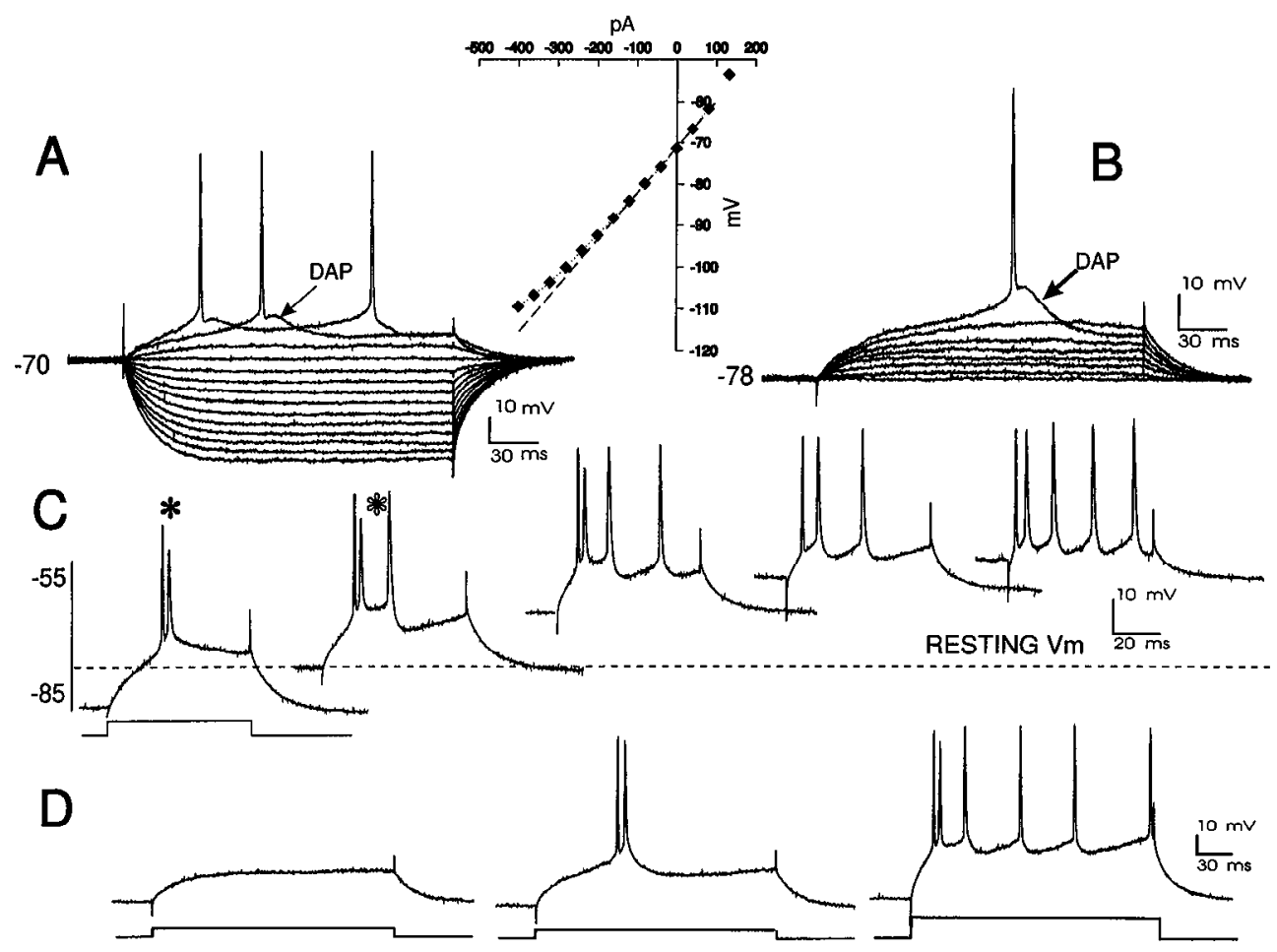

Figure 5. Electrophysiological characteristics of a typical IB PFC neuron: $A$, Voltage deflections and firing responses to injection of a scrics of hyperpolarizing and depolarizing current steps $(200 \mathrm{msec}, 40 \mathrm{pA}$ per step). The inset shows a typical voltage-current plot in which the slope resistance displays linearity in the membrane voltage range between -60 and $-95 \mathrm{mV}$. The slope resistance, extrapolated from the linear range of this cell (dotted line), is $100 \mathrm{M} \Omega$. Membrane inward rectification in the hyperpolarized voltage range, as indicated by the upward tilt of the plot, occurred beyond -95 $\mathrm{mV}$. $B$, Membrane voltage responses at subthreshold and at threshold to firing evoked by intracellular injection of a series of depolarizing pulses (200 msec, $50 \mathrm{pA}$ step). Note that the action potential is followed by a prominent DAP (arrow). This prominent postspike DAP had a duration of 10 to 20 $\mathrm{ms}$. C, A fixed depolarizing pulse $(100 \mathrm{pA})$ was injected intracellularly as the steady-state $V_{\mathrm{m}}$ was adjusted (by continuous DC current injection) from -85 to $-55 \mathrm{mV}$. At $V_{\mathrm{m}} \geq-85 \mathrm{mV}$ (left to right), a burst of spikes consisted of a high-frequency $\left(100-200 \mathrm{~Hz}\right.$ ) spike doublet (filled asterisk). As the $V_{\mathrm{m}}$ was held more positively, single spikes firing merged into the DAP of the spike doublet (open asterisk). With additional membrane depolarization, the bursting response transformed into firing of single spikes with progressively longer interspike intervals (i.e., spike-frequency adaptation). The dotted line denotes the resting $V_{\mathrm{m}} . D$, The same cell was held at $-75 \mathrm{mV}$ as depolarizing current pulses of progressively greater amplitude were injected. A spike doublet initially was observed as the amplitude of the depolarizing current pulses were increased (left to right). Additional increases elicited a series of single spikes with progressive spike-frequency adaptation. In all of the IB neurons analyzed, the maximum number of spikes elicited per burst was the obligatory initial spike doublet. 


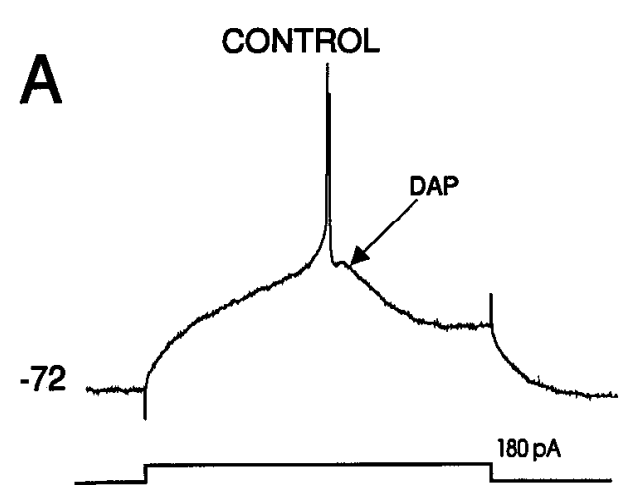

TTX

B
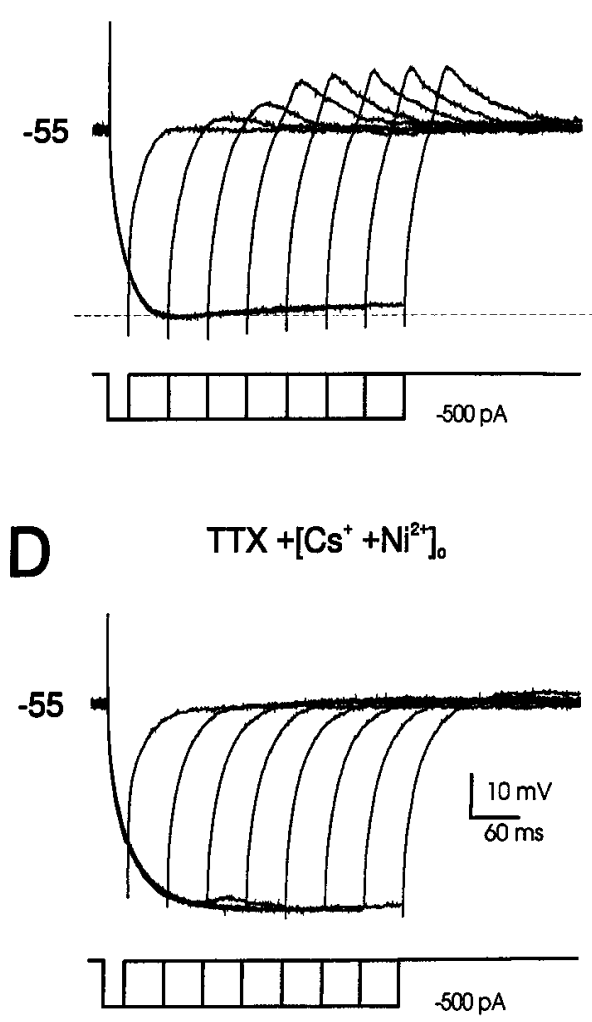

\author{
$0 \mathrm{Ca}^{2+}, 10 \mathrm{mM} \mathrm{Mg}^{2+}$
}

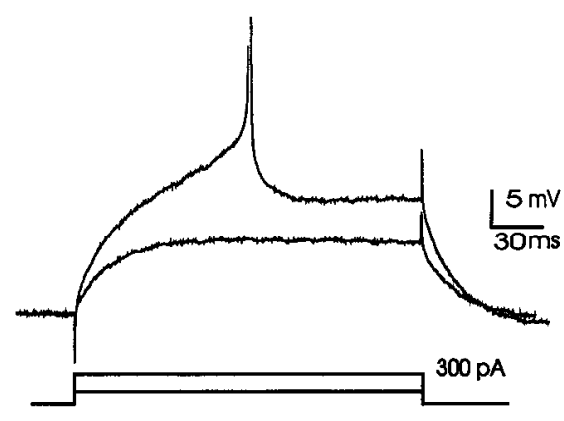

$\pi \mathrm{TX}+\left[\mathrm{Cs}^{+}\right]_{0}$

C
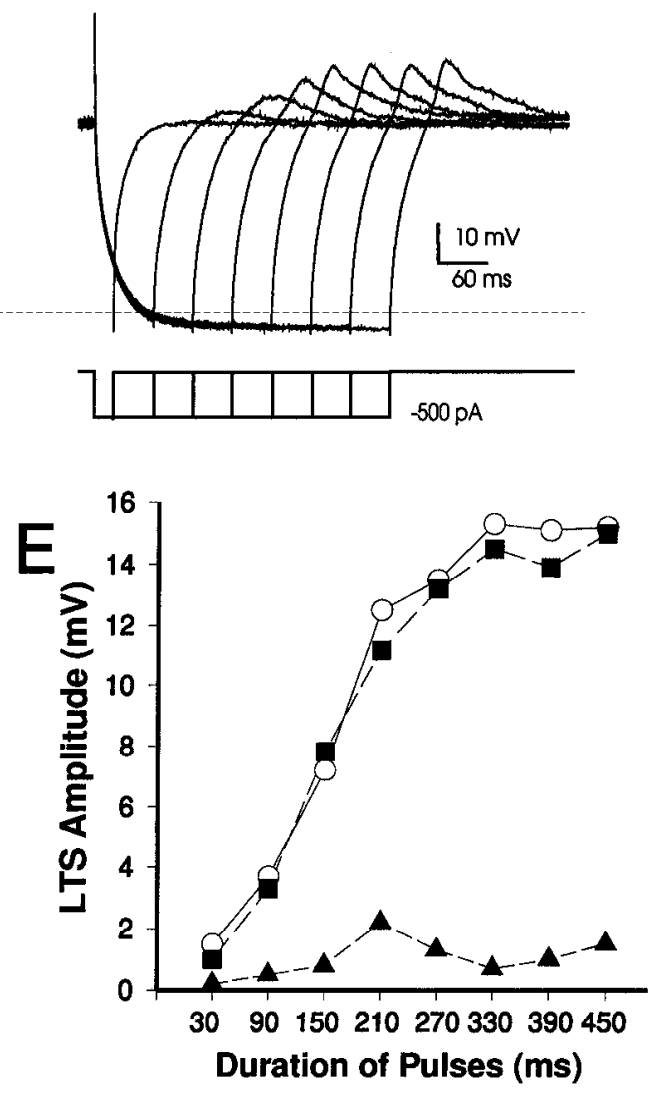

Figure 6. $\mathrm{Ca}^{2+}$ currents mediating the postspike DAP and the LTS in IB neurons of the PFC. $A$, The postspike DAP was removed completely after perfusion with media containing no extracellular $\mathrm{Ca}^{2+}$ (plus $10 \mathrm{mM} \mathrm{Mg}^{2+}$ ). Note that under this condition, a larger depolarizing pulse was necessary to evoke spike discharge. $B$, In the presence of TTX $(0.5$ $\mu \mathrm{M})$, LTS were evoked after the injection of hyperpolarizing current pulses $(500 \mathrm{pA}$, at $60 \mathrm{~ms}$ increments) to deinactivate LTS. $C$, Bath application of $\mathrm{CsCl}(2 \mathrm{mM})$ blocked the weak timedependent hyperpolarizing inward rectification mediated by $\mathrm{I}_{\mathrm{h}}$, but $\mathrm{Cs}^{+}$did not change the amplitude of the LTS. $D$, Addition of $\mathrm{Ni}^{2+}(200 \mu \mathrm{M})$ in the TTXcontaining perfusate blocked the LTS completely. $E$, A graph showing the time-dependent activation of the LTS, with progressive increase in LTS amplitude as the duration of the hyperpolarizing pulses was prolonged. Open circle indicates in TTX $(0.5 \mu \mathrm{M})$; filled squares, in TTX $+\mathrm{Cs}^{+}(2 \mathrm{~mm})$; and filled triangle, TTX $+\mathrm{Cs}^{+} \mathrm{Ni}^{2+}(200$ $\mu \mathrm{M})$. depolarizations caused by injections of positive current. Hence, the steady-state V-I plot showed a typical downward bend as illustrated in Fig. $4 B$.

\section{IB neurons (Fig. 5)}

By far the most frequently recorded type of neuron in layers V-VI of the PFC ( $n=63,63 \%$ ) was classified as IB (also called phasic-tonic firing in other studies, e.g., van Brederode and Snyder, 1992). IB neurons had a mean resting $V_{\mathrm{m}}$ of $-72 \pm 1.2$ $\mathrm{mV}$. The voltage-current plot of this type of PFC cell was linear in the membrane voltage range between -60 and -95 $\mathrm{mV}$, yielding a mean slope resistance of $109 \pm 8 \mathrm{M} \Omega$. The mean $\tau$ of the IB PFC neurons was $17.9 \pm 0.9 \mathrm{msec}$, and the mean firing threshold was $-51.8 \pm 1 \mathrm{mV}$ (Table 1).

\section{Repetitive firing patterns}

When activated from rest by an intracellular current pulse, IB cells showed a distinctive depolarizing afterpotential (DAP), which followed immediately after each incompletely repolarized action potential (Fig. $5 A, B$ ). The generation of this DAP was dependent on $\left[\mathrm{Ca}^{2+}\right]_{\mathrm{o}}$, because removal of extracellular $\mathrm{Ca}^{2+}$ (plus an addition of $10 \mathrm{~mm} \mathrm{Mg}^{2+}$ ) blocked the postspike DAP (Fig. 6C). The presence of a postspike DAP in IB neurons represented one of the key features that distinguished this cell type from RS neurons.

When the steady-state $V_{\mathrm{m}}$ was adjusted to more negative than $-65 \mathrm{mV}$, injection of a fixed-amplitude depolarizing pulse evoked a doublet of fast spikes rising over a depolarizing envelope. As the 

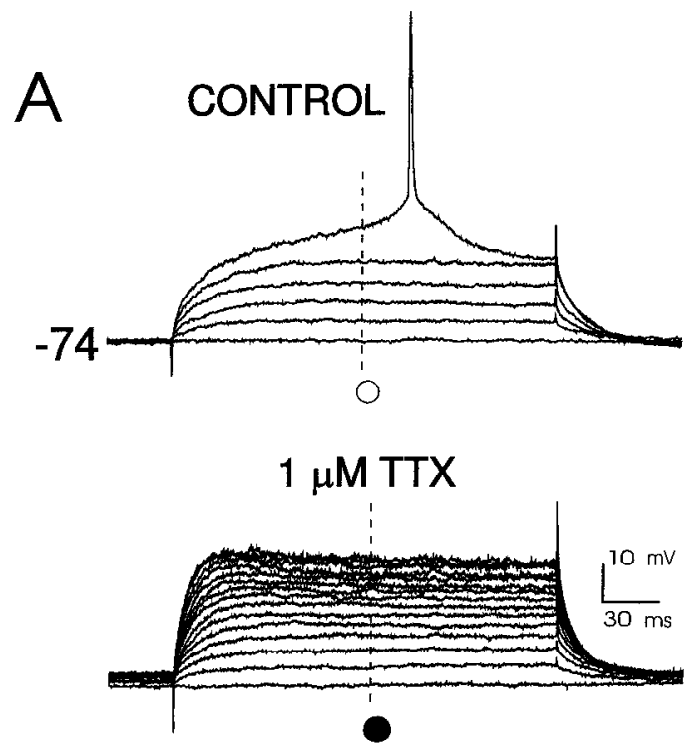

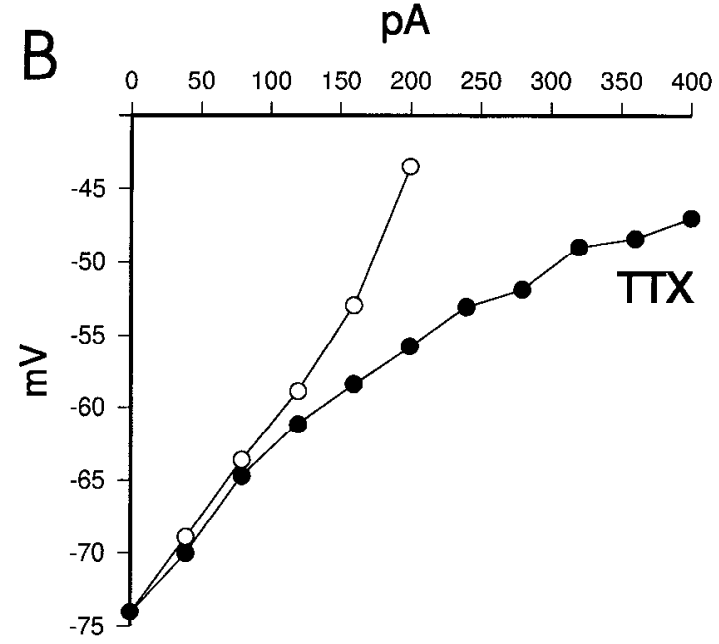

Figure 7. Voltage-dependent anomalous rectification in the depolarized voltage range in an IB PFC neuron. $A$, The underlying current that mediates the inward rectification in the depolarized range is sensitive to TTX blockade. After bath application of TTX (1 $\mu \mathrm{M})$, additional depolarizing pulses unveiled activation of an outward rectifying conductance. $B$, This outward rectification is responsible for the downward bend of the V-I plot TTX (filled circles ). Open circles indicate control.

steady-state $V_{\mathrm{m}}$ was adjusted to more positive potentials, single spikes following the initial doublet merged into the depolarizing envelope (Fig. 5C, open asterisk). After the initial spike doublet, IB neurons fired single spikes with progressive spike frequency adaptation (Fig. 5). When held at a constant resting potential, progressive increments in the amplitude of the depolarizing pulse evoked an initial spike doublet that was followed by a series of single spikes with progressively longer interspike intervals (i.e., spike frequency adaptation). Unlike in RS neurons, the postspike AHPs in IB neurons were of lower amplitude but longer duration.

\section{Anomalous rectification}

The depolarizing envelope evoked from hyperpolarized potentials as described above resembled the low-threshold $\mathrm{Ca}^{2+}$ spike (LTS) (Fig. 5, filled asterisk) observed in many other types of central neurons, including cortical neurons (Franz et al., 1986; Llinas, 1986). The LTS is partly responsible for the depolarizing inward rectification, and it is mainly $\mathrm{Ca}^{2+}$-mediated because reduction of $\left[\mathrm{Ca}^{2+}\right]_{\mathrm{o}}$ to $0.5 \mathrm{~mm}$ diminished its amplitude $(n=7)$ (Fig. $6 A$ ) markedly. Activation of the LTS in IB neurons was dependent on multiple factors. At membrane potentials more positive than -55 $\mathrm{mV}$, the low threshold $\mathrm{Ca}^{2+}$ current was inactive. Hyperpolarizing the membrane from $-55 \mathrm{mV}$ to potentials more negative than $-70 \mathrm{mV}$ for $100-500 \mathrm{msec}$ was necessary to achieve a voltage- and time-dependent removal of inactivation of the low-threshold $\mathrm{Ca}^{2+}$ conductance (Fig. $6 B$ ). When the activated LTS brought the membrane to firing threshold (varying between -45 and -53 $\mathrm{mV}$ ), a high-frequency burst of conventional $\mathrm{Na}^{+}-$and $\mathrm{K}^{+}$dependent spikes was triggered (data not shown). The LTS also showed a time-dependent increase in amplitude that was observed most clearly when $\mathrm{Na}^{+}$and inwardly rectifying $\mathrm{K}^{+}$conductances were blocked by TTX $(1 \mu \mathrm{M})$ and $\mathrm{CsCl}(2.5 \mathrm{~mm})$, respectively (Fig. $6 B, C)$. Consistent with a previous study performed in frontal cortical neurons (Ye and Akaike, 1993), the LTS is sensitive only to high concentrations of $\mathrm{Ni}^{2+}$. In the present study, the LTS was blocked only partially by $100 \mu \mathrm{M} \mathrm{Ni}{ }^{2+}$, and $200 \mu \mathrm{M} \mathrm{Ni}{ }^{2+}$ was necessary to achieve complete blockade (Fig. $6 D, E$ ).
While evoking LTS using hyperpolarizing current pulses that deflected the $V_{\mathrm{m}}$ more negative than $-95 \mathrm{mV}$, a weak timedependent slow inward rectification in the hyperpolarizing voltage range was observed in $10 \mathrm{IB}$ neurons. This weak inward rectification is represented as an upward tilt in the V-I plot illustrated in Fig. $5 A$. This inward rectification is sensitive to bath application of $\mathrm{Cs}^{+}(2.5 \mathrm{~mm})$ (Fig. 6B,C) and, thus, resembles the hyperpolarization-actived mixed cationic current $\left(I_{h}\right)$ that is activated by membrane hyperpolarization.

A time-dependent slow membrane inward rectification was observed in $30 \mathrm{IB}$ neurons in the voltage range more positive than $-70 \mathrm{mV}$. This inward rectification resulted in an upward bend in the depolarized range of the $\mathrm{V}-\mathrm{l}$ plot ( Fig. $7 \mathrm{C}^{\prime}$ ). The inward rectification was blocked completely by bath application of TTX $(1 \mu \mathrm{M})$ or intraccllular injection of QX-314, suggesting that it was mediated by a TTX-sensitive $\mathrm{Na}^{+}$current (Fig. 7) $(n=9 / 9$ cells).

After TTX treatment, an outward rectification was revealed. It was $\mathrm{K}^{+}$-mediated, because it was blocked by bath application of 4-AP ( $2 \mathrm{~mm}$ ) in all four IB cells tested. An identical blockade of the outward rectifier was also observed in five RS neurons. This outward rectification resulted in a downward bend of the V-I plot as shown in Fig. 7D. Coapplication of TTX and 4-AP blocked inward and outward rectifications, respectively, and linearized the $\mathrm{V}$-I plot (Fig. 8). These $\mathrm{Na}^{+}$and $\mathrm{K}^{+}$currents, in conjunction with the low-threshold $\mathrm{Ca}^{2+}$ current, which can also be activated at the subthreshold range after previous hyperpolarization, influences membrane excitability in the subthreshold range (Sutor and Zieglgansberger, 1987).

\section{Subthreshold membrane oscillations and pacemaker firing}

One type of IB neuron (type 1) [18/60 (30\%)] showed a narrow frequency subthreshold oscillation that resembled that observed in RS cells. Spike clusters sometime occurred between periods of membrane oscillations in these cells (Fig. $9 \mathrm{~A}$, filled asterisks). The narrow frequency subthreshold oscillations were limited by the voltage-dependent activation of a delayed outward rectifier. In a second type of IB neurons (type 2) [(42/60) 70\%], spike firing was 

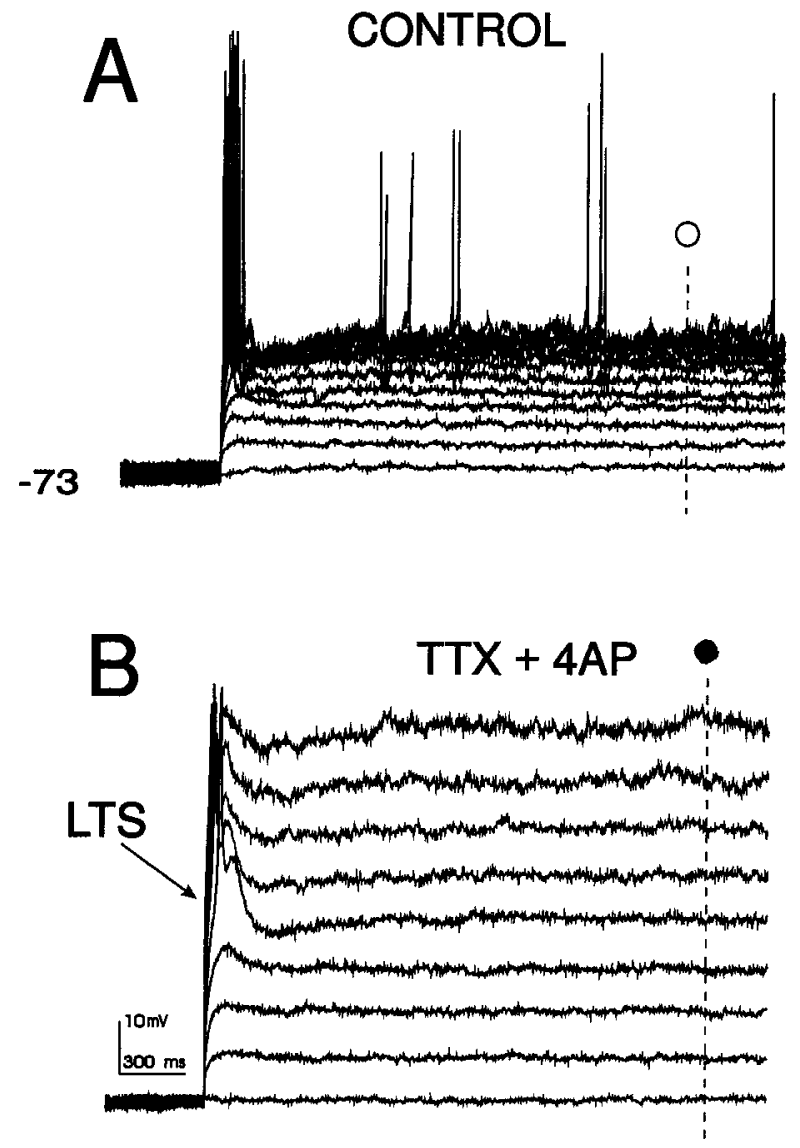

$450 \mathrm{pA}$
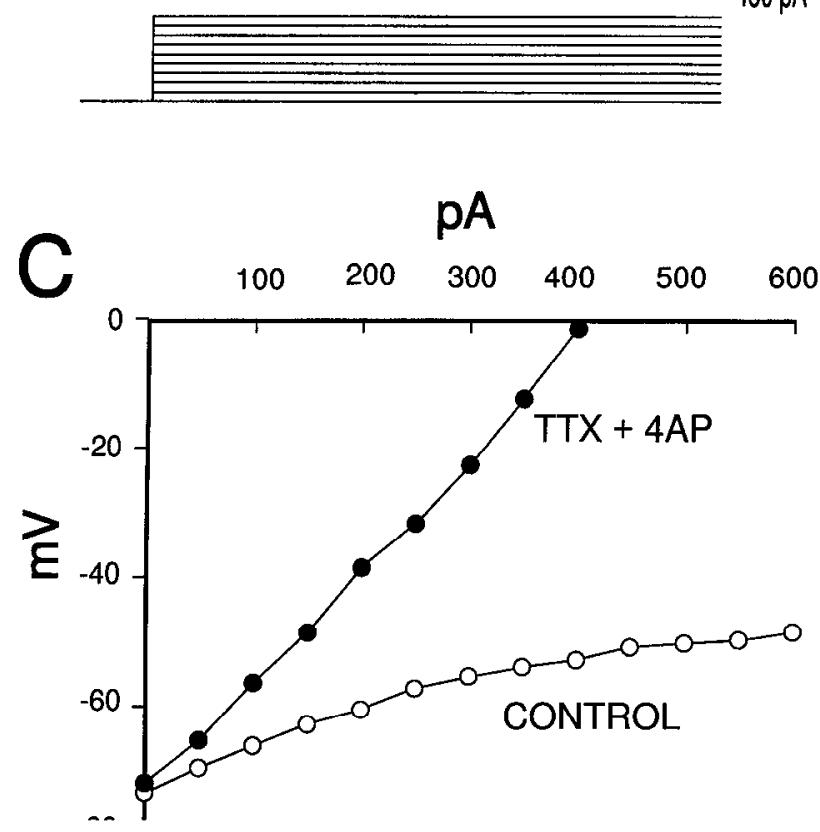

Figure 8. Subthreshold membrane oscillation and outward rectification in IB PFC neurons. $A$, In one third of IB neurons, sustained membrane depolarization induced by injection of a long depolarizing pulse evoked a subthreshold membrane oscillation similar to that observed in RS neurons. Note that the initial spike burst was likely caused by activation of the low-threshold $\mathrm{Ca}^{2+}$ spike by the same protocol. In addition, a prominent membrane outward rectification, activated at approximately $-58 \mathrm{mV}$ opposed any additional membrane depolarization. $B$, Bath application of TTX $(1 \mu \mathrm{M})$ and 4-AP (2 mM) abolished much of the outward rectification. TTX was used to suppress the massive discharge of EPSPs and spikes caused by a presynaptic neurotransmitter release action of 4-AP (Thesleff, 1980). TTX alone blocked the subthreshold membrane oscillations but did not change the superimposed on the oscillating waves of the membrane potential. In contrast to type 1 IB neurons, oscillations in type 2 IB neurons were unaffected by membrane outward rectification. As a result, there was a linear increase in firing frequency with membrane depolarization, leading to a broad-frequency pacemaker-like firing.

\section{ROB neurons}

\section{Repetitive firing pattern}

Present only in layers VI was a small population of neurons (see Fig. $10 ; n=13,13 \%$ ) that fired spontaneously with sustained rhythmicity. This type of cortical neuron has been classified previously as ROB, because when depolarized by a sustained depolarizing pulse, it fires repetitive bursts of action potentials (Fig. 10A) (Silva et al., 1991). In three cells tested, the spontaneous firing at rest alternated between bursts and single spikes (Fig. $11 A$ ). ROB neurons had a mean resting membrane potential of $-65 \pm 5 \mathrm{mV}$, a mean $\tau$ of $12.3 \pm 0.8 \mathrm{msec}$, a mean $R_{\mathrm{N}}$ of $83 \pm 9.5$ $\mathrm{M} \Omega$, and a mean firing threshold of $-58 \pm 3 \mathrm{mV}$, which is lower than both the RS and IB cells.

Injection of a depolarizing pulse induced a transient burst of spikes when the steady-state $V_{\mathrm{m}}$ of these cells were held (via continuous DC current injection) from more negative potentials (below resting) to more depolarized potentials (above resting). A typical bursting complex consisted of a single spike that was followed by two to four broader spikes of smaller amplitudes (the number of spikes within the bursting complex varied according to the quality of microelectrode impalement). At more depolarized $V_{\mathrm{m}}$, the same depolarizing pulse triggered repetitive burst firing with an abrupt transition to single-spike firing (Fig. 11B).

At resting potential, injection of a depolarizing pulse elicited a single spike, which was followed immediately by a small AHP, a postspike DAP, and a medium-length AHP (mAHP) (Fig. 10C). Additional increases in the intensity of the depolarizing pulse elicited a single spike, which was followed by a bursting complex of two to four spikes that often rose on top of a DAP. A postburst $\mathrm{mAHP}$ of 3-6 $\mathrm{mV}$ followed each bursting complex. In response to sustained membrane depolarization (e.g., >1-3 sec) ROB neurons fired in repetitive bursts (Fig. 11B). Bursts were pacemakerlike, and the bursting frequency was almost linearly proportional to the membrane potential (Fig. 11C).

The bursting complex and the accompanied postburst AHP were eliminated by lowering $\left[\mathrm{Ca}^{2}\right]_{\mathrm{o}}(0.5 \mathrm{~mm})$ and elevating $\left[\mathrm{Mg}^{2+}\right]_{\mathrm{o}}(10 \mathrm{~mm})$ in all five neurons tested (Fig. 12). Under these conditions, the same depolarizing pulses evoked only single-spike firing, which was followed immediately by a less pronounced DAP (Fig. 12A).

A time- and voltage-dependent LTS mixed with a burst of several spikes also was present in this cell type. Like the LTS in IB neurons, hyperpolarization of variable durations was necessary to deinactivate the LTS in ROB cells (Fig. $12 B)(n=3 / 3)$. After bath application of TTX $(1 \mu \mathrm{M})$ and TEA $(20 \mathrm{mM})$, as the steady-state $V_{\mathrm{m}}$ was held at $-50 \mathrm{mV}$, a short depolarizing pulse $(25 \mathrm{msec})$ triggered regenerative high-threshold $\mathrm{Ca}^{2+}$ spikes (HTS). Spon-

$\longleftarrow$

membrane outward rectification (data not shown). Note that after the blockade of the outward rectifying current, initial transient depolarizing LTS was revealed readily by the same protocol. $C$, Voltage-current plot illustrating the removal of the outward rectification of the control by the TTX + 4-AP treatment. The downward deflection of the control plot (open circle) is linearized after this latter treatment (filled circle). 


\section{INTRINSIC BURSTING (1)}

Figure 9. Voltage dependent subthreshold membrane oscillations and rhythmic pacemaker-like firing in IB PFC neurons. $A$, One-third of all IB PFC neurons (type 1) recorded exhibited subthreshold membrane oscillation (left $)$. When spikes were present, they occurred in clusters (asterisk), and this firing mode was distinctively different from the firing mode of the RS PFC neurons described in Figure 3. The ocillatory frequencies (filled circles) were restricted within a narrow bandwidth of 8 to $12 \mathrm{~Hz}$, perhaps because of strong outward rectification that prevented the membrane from being depolarized further by the depolarizing current pulses (right). However, the amplitude of the oscillation (open circles) increased progressively with membrane depolarization. $B$, In marked contrast, the remaining majority (two thirds) of all IB PFC neurons (type 2) fired in a rhythmic pacemaker-like mode on membrane depolarization. Note the regularity of the firing pattern on progressive membrane depolarization by DC current injections.

Figure 10. Electrophysiological characteristics of a typical ROB PFC neuron. $A$, Distinct features of a typical $\mathrm{ROB}$ neuron in response to depolarizing and hyperpolarizing current pulses included an instantaneous hyperpolarizing sag (arrow) when membrane was hyperpolarized beyond $-85 \mathrm{mV}$, repetitive bursting in response to a depolarizing pulse, a postburst mAHP that separates each burst, and voltage-dependent rebound bursts after the termination of hyperpolarizing pulses. $B$, V-I plot showing the membrane inward rectification (upward bend from the linear dashed line) resulting from the instantaneous hyperpolarizing sag (open circle) and the timedependent steady-state voltage response resulting from the hyperpolarizationactivated inward current $I_{h}$ (open square). $C$, Steady-state membrane voltages were adjusted to different potentials (from -85 to $-56 \mathrm{mV}$ ) via continuous DC current injection (left to right). Depolarizing pulses $(100 \mathrm{~ms})$ injected evoked bursting responses (asterisk). Additional membrane depolarization transformed repetitive bursts of firing of single spikes. $D$, When held at resting, increasing the amplitude of the depolarizing pulse first evoked a single spike, which was followed immediately by a DAP. Additional increases of the depolarizing pulse amplitude elicited a burst of spikes that were derived from the DAP. The burst was followed by a postburst AHP and, subsequently, a single spike. Greater depolarization now switched the cell to firing spikes after the initial burst.
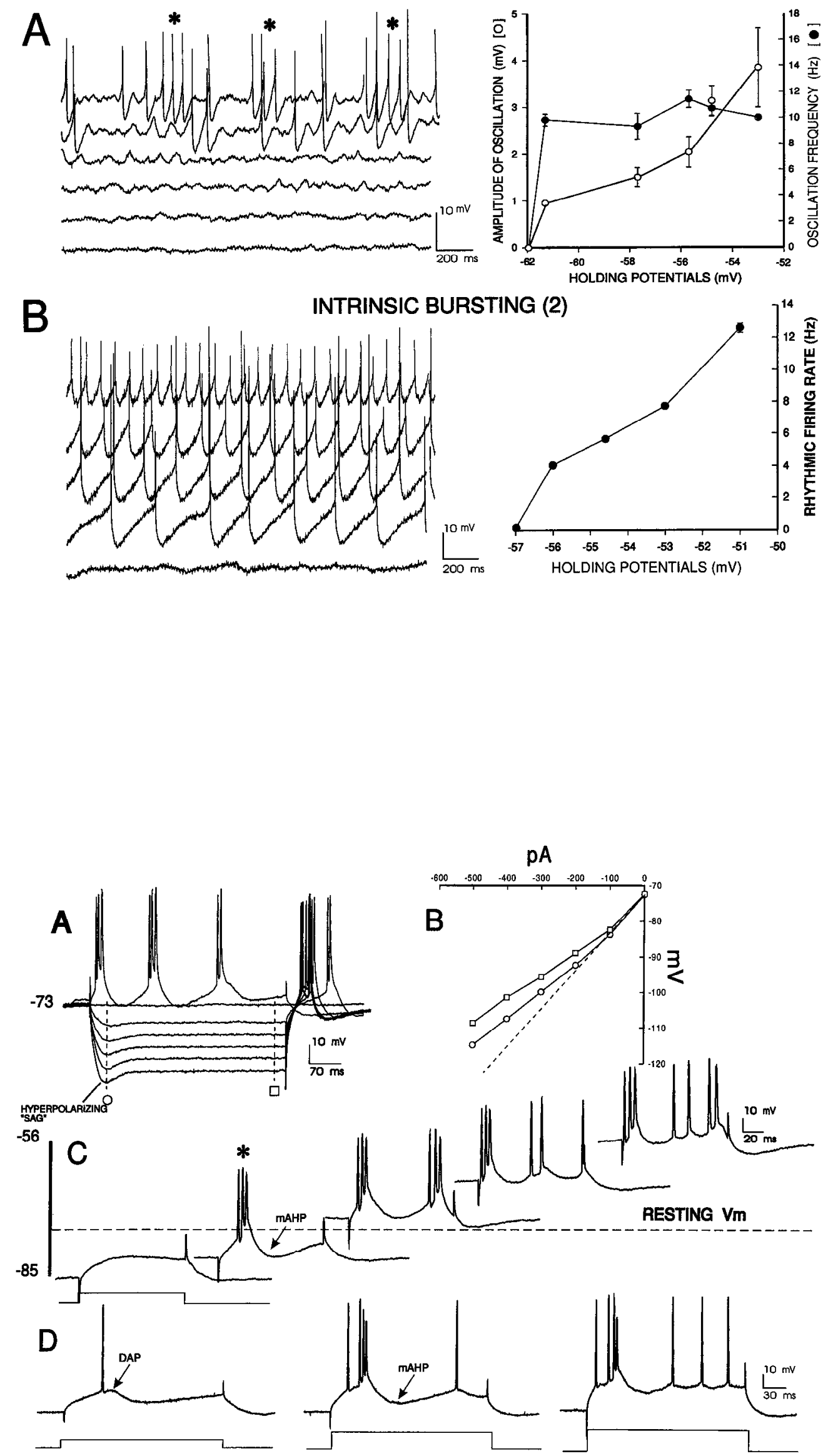

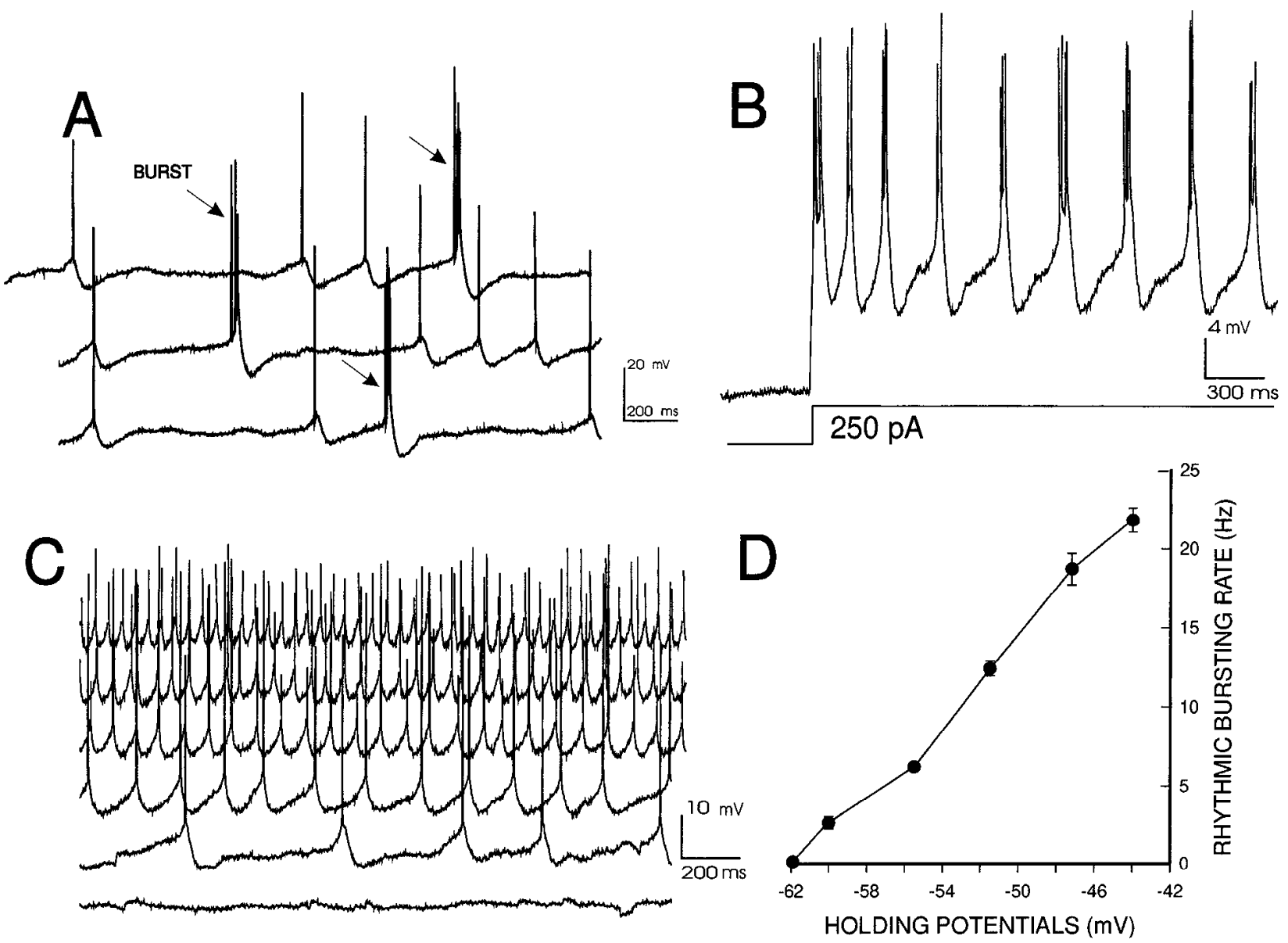

Figure 11. Firing patterns of ROB neuron. A, Spontaneous repetitive oscillatory bursting behavior of a ROB cell with spontaneous firing switching between bursting and single spikes. $B, \mathrm{ROB}$ behavior in response to sustained membrane depolarization ( $250 \mathrm{pA})$. $C, D$, Pacemaker-like burst firing on membrane depolarization. Note that the firing rate increased almost linearly with membrane depolarization and was not restricted by an outward rectification.
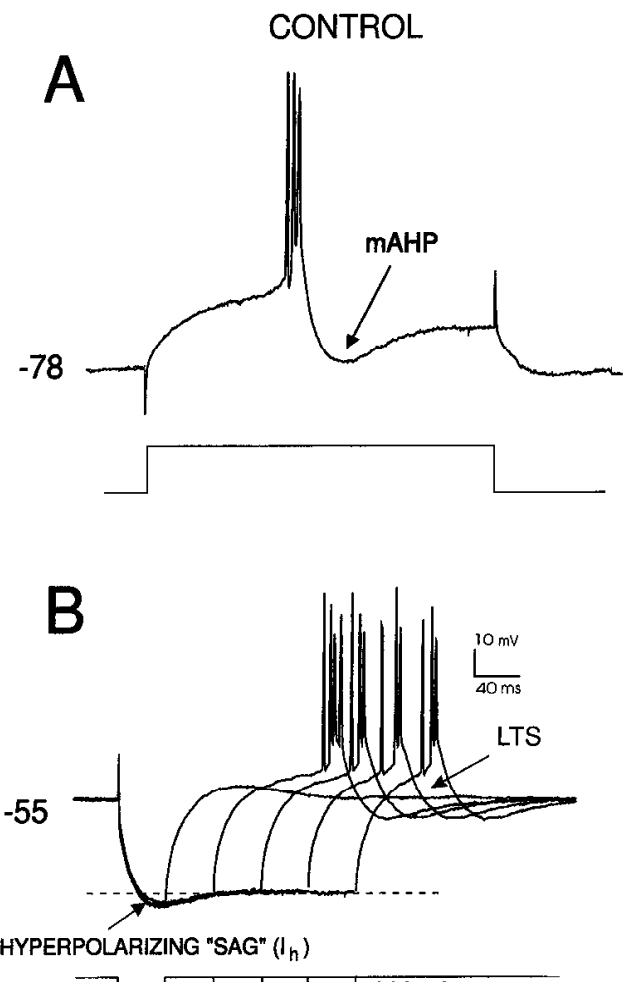

\section{$0.5 \mathrm{mM} \mathrm{Ca}^{2+}, 10 \mathrm{mM} \mathrm{Mg}^{2+}$}

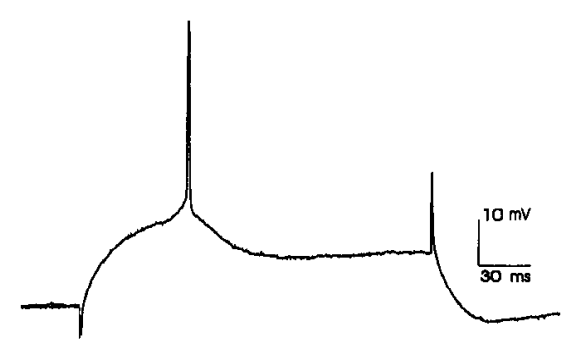

$400 \mathrm{pA}$

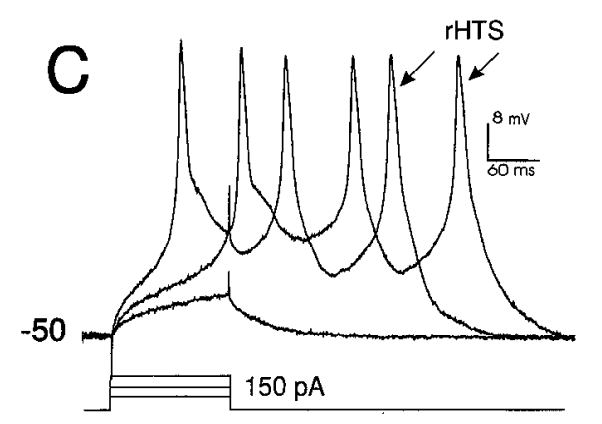

Figure 12. $\mathrm{Ca}^{2+}$-mediated potentials recorded in ROB PFC neurons. $A$, A single burst and its associated postburst AHP evoked from an intracellularly injected current pulse (left). Reducing extracellular $\mathrm{Ca}^{2+}$ to $0.5 \mathrm{~mm}$ and adding 10 $\mathrm{mM} \mathrm{Mg}^{2+}$ abolished bursting (right). Note that a low-amplitude postspike DAP still persists under this condition. $B$, A time- and voltage-dependent LTS (data not shown) also was present prominently in this cell type. Note that the LTS gave rise to $\mathrm{Na}^{+}$spike bursts and the associated postburst AHPs. Note also the time-dependent inward rectification (hyperpolarizing sag), which typically is induced by $\mathrm{I}_{h}$. This sag also represents a typical electrophysiological feature of this PFC cell type. $C$, In the presence of TTX $(1 \mu \mathrm{M})$ and TEA (20 $\mathrm{mM}), \mathrm{Ca}^{2+}$ rHTS were elicited by intracellular current pulses when the cell was held at $-50 \mathrm{mV}$. 
taneous firing of regenerative HTS could be sustained with continuous injection of DC current. HTS firing frequency increased with additional membrane depolarization (Fig. 12C, right) $(n=$ $7 / 7$ ). The sustained period of firing regenerative HTS outlasted the short duration of the injected current pulses.

\section{Anomalous rectification}

As shown in Figures 10 and $12 B$, a transient hyperpolarizing sag with increasing amplitude was observed in these cells in response to incremental hyperpolarizing pulses elicited from higher than $-80 \mathrm{mV}$. Beyond approximately $-70 \mathrm{msec}$, this "sag" tended to push the membrane potential back towards resting values. The hyperpolarizing sag resulted in a typical upward bend in the hyperpolarizing portion of the current-voltage plot when compared with the extrapolated linear portion (dotted line) (Fig. 10). In addition, a transient burst of spikes resulted from the termination of the $100 \mathrm{msec}$ hyperpolarizing pulse. Similar to the IB neurons, this rebound burst was likely to be derived from a typical time- and voltage-dependent activation of the transient lowthreshold $\mathrm{Ca}^{2+}$ spikes that elicited a burst of $\mathrm{Na}^{+}-\mathrm{K}^{+}$spikes (Fig. $12 B$ ). The prominent hyperpolarization-activated time-dependent transient inward rectification and the distinct bursting characteristics of the ROB cells were the electrophysiological features that clearly distinguished them from the other cell types found in the PFC.

\section{IM neurons (Fig. 13)}

A small group of nonbursting PFC neurons (4/99 cells; 4\%) was recorded in the upper portions of layers $\mathrm{V}$. These cells are called intermediate, because their electrophysiological characteristics were intermediate between RS and IB cells. As shown in Table 1, the intrinsic membrane properties of the IM neurons were not significantly different from that of typical RS cells. They had a mean $V_{\mathrm{m}}$ of $-71.75 \pm 3.6 \mathrm{mV}$, a mean $R_{\mathrm{N}}$ of $90 \pm 8 \mathrm{M} \Omega$, a mean firing threshold of $-50.7 \pm 2 \mathrm{mV}$, and a $\tau$ of $16.5 \pm 2 \mathrm{msec}$ (Table 1).

\section{Repetitive firing pattem}

Electrophysiologically, these neurons were characterized by the presence of both a fast afterhyperpolarization (fAHP) and an mAHP. A small (3-4 $\mathrm{mV}$ ) postspike DAP was present between the fAHP and the mAHP when spikes were evoked by current pulses injected at rest. At more depolarized potentials (at less than $-60 \mathrm{mV}$ ), the fAHP and the DAP diminished. As the cell was depolarized to values more positive than $-60 \mathrm{mV}$, only the postspike mAHP followed each spike (Fig. 11). At depolarized potentials, cvoked repetitive firing was accompanied by strong spike-frequency adaptation and was indistinguishable from the typical RS cells.

When held at the same $V_{\mathrm{m}}$, progressive increases in the amplitude of the injected pulse also induced spike firing that was accompanied by the postspike fAHP, DAP, and mAHP. Although the presence of a DAP usually indicates a tendency of a cell to fire in bursts, we failed to induce bursting in all IM cells using the same current injection protocols that induced bursting in IB and ROB cells.

\section{Antidromic responses and double-labeling of PFC output neurons that projected to the NAC}

Antidromic responses (as outlined in Materials and Methods) were observed in 12 of 75 PFC neurons tested in this study (Fig. 14). All except one of these neurons were classified electrophysiologically as IB neurons. The remaining cell was a ROB neuron. The IB PFC neurons that responded antidromically to NAc stimulation were distributed approximately in the caudoventral prelimbic and anterodorsal infralimbic regions of the PFC. Stimulation that evoked antidromic responses were delivered primarily to the anteromedial portion of the NAc.

The mean onset latency of the antidromic response was $4.7 \pm$ $0.75 \mathrm{msec}$ for the IB neurons. In all IB cells, there was a prominent postspike DAP that was initiated in the incompletely repolarized phase of the spike, as shown in Figure 14. The amplitude of the postspike DAP increased with membrane hyperpolariza-
Figure 13. Electrophysiological characteristics of the IM cells. $A$, Membrane voltage deflections in response to a progressive series of ( $50 \mathrm{~ms}$ steps) depolarizing and hyperpolarizing pulses. $B$, V-I plot showed a linear response in the voltage range between -50 and $-110 \mathrm{mV}$. $C$, Typical spike discharge showed a fAHP followed by a DAP and then a mAHP. $D$, Spike discharge by a depolarizing pulse $(100 \mathrm{pA})$ as the steady-state $V_{m}$ was adjusted from -80 to $-55 \mathrm{mV}$ (left to right). Note that no bursting occurred at any holding potentials. The spike train evoked showed marked spikefrequency adaptation. $E$, Progressive increases of depolarizing current pulses as the $V_{\mathrm{m}}$ was held constant also evoked a spike train with marked frequency adaptation. Note also that a DAP was present only after the first spike and diminished with subsequent spikes evoked.

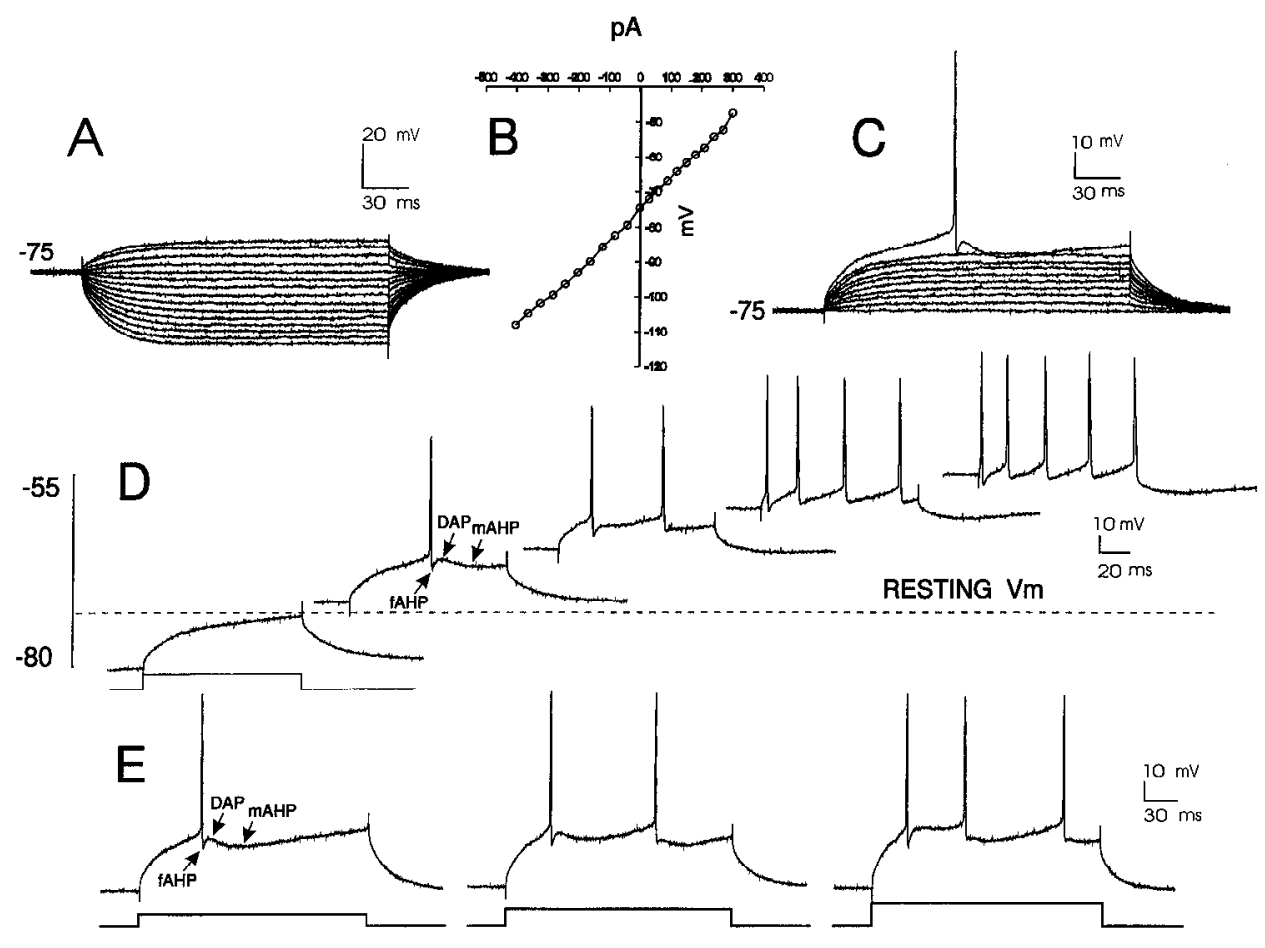



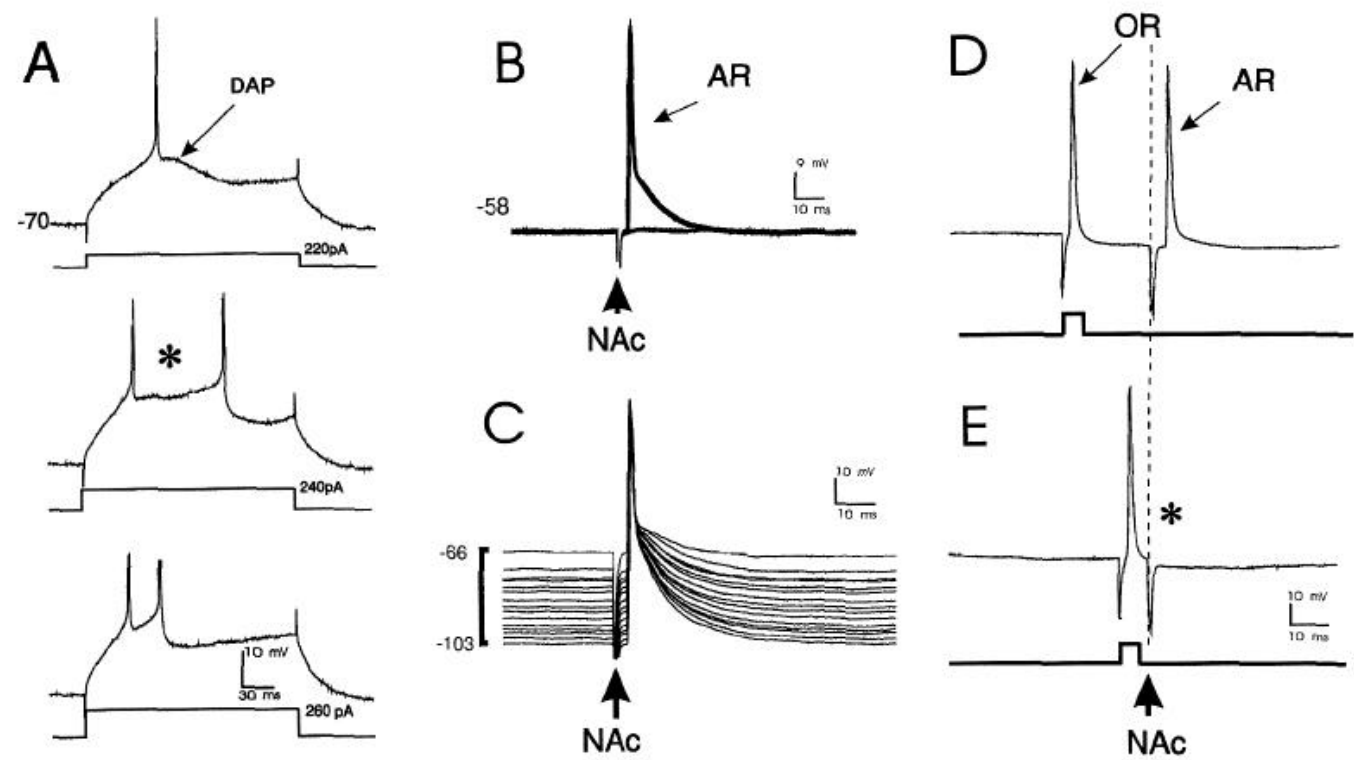

$\mathrm{F}$

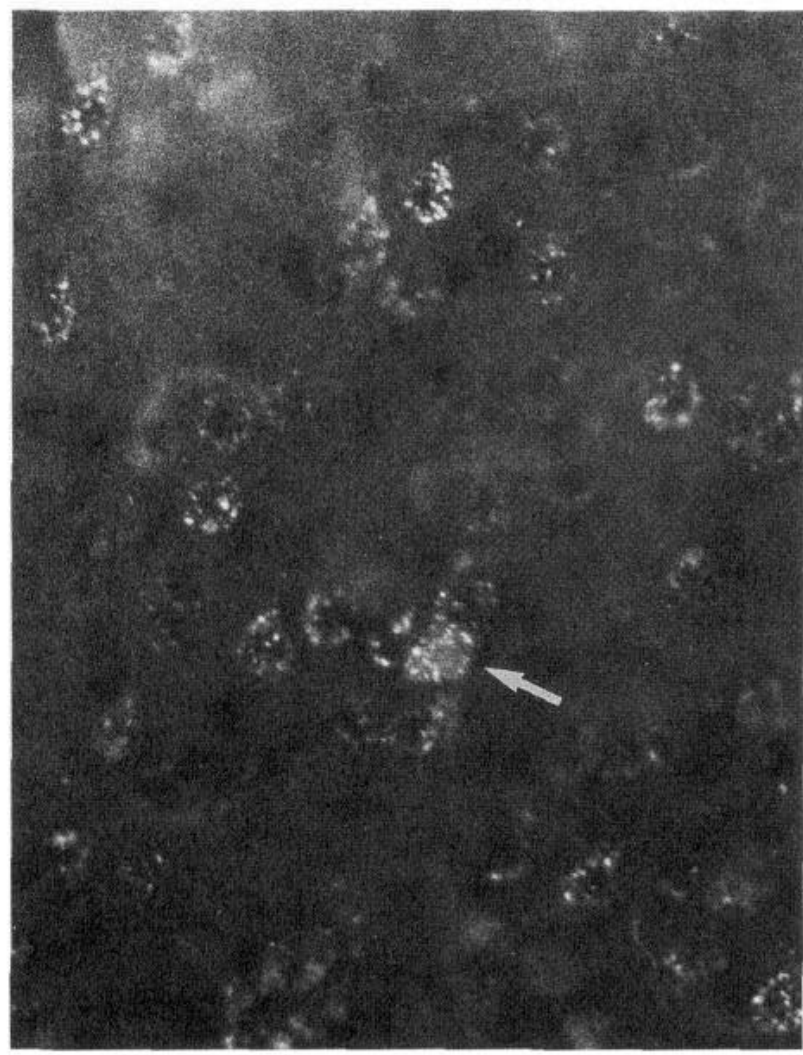

$\mathrm{G}$

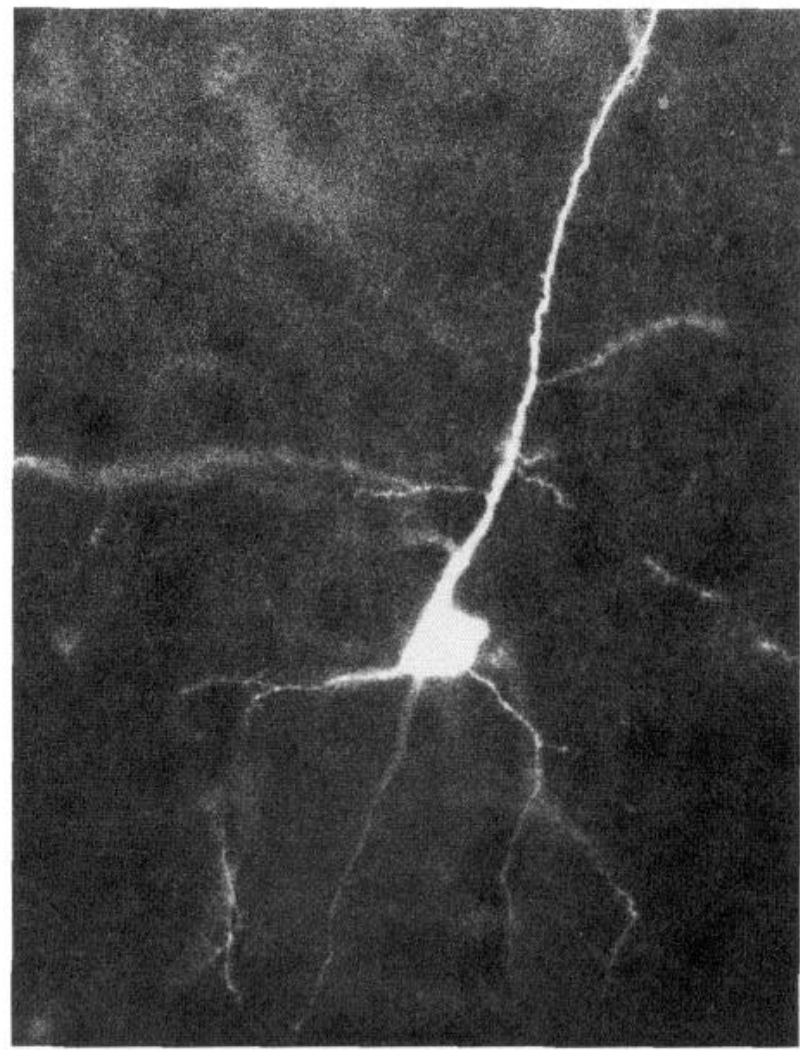

Figure 14. Antidromic responses of PFC neurons to NAc stimulations. A, Typical voltage deflections caused by injection of a series of current pulses in an IB neuron. Note the prominent postspike depolarizing afterpotential in this cell type. $B$, All-or-nothing antidromic response $(A R)$ of the same neuron of the antidromic responses with changes in holding potential. $D, E$, "Collision" (asterisk) of the AR with an intracellularly evoked, orthodromically traveling spike $(O R) . F$, Fluorescent photomicrographs of a double labeled IB PFC $\rightarrow$ NAc neuron. This PFC $\rightarrow$ NAc neuron is loaded with retrogradely to threshold stimulation (upward arrow) of the NAc. Note the invariant onset latency. Suprimposed traces from seven trials. $C$, Invariant onset latency transported rhodamine microbeads that were injected $6-8 \mathrm{~d}$ before into the NAc. The arrow indicates the rhodamine microbead-filled neuron that was recorded electrophysiologically. $G$, FITC fluorescence in the same IB PFC neuron that was filled with biocytin. This double labeling indicates that the same PFC neuron represents a projection neuron to the NAc.

tion, whereas the onset latency of the antidromic spike did not shift on progressive membrane hyperpolarizations via DC current injection (Fig. 14). The majority (8/12) of IB neurons that responded antidromically to NAc stimulation displayed broad- frequency pacemaker-type firing (type 2), whereas the remaining 4 neurons displayed subthreshold narrow-frequency membrane oscillations (type 1). Because of the unsectioned thick slices (400$450 \mu \mathrm{m}$ ) that we used to assess the somadendritic profiles of PFC 
neurons, it was not possible to trace the axons of the antidromically activated biocytin-stained neurons to the NAc $(n=3)$.

In addition to the 12 PFC neurons that were activated antidromically by NAc stimulation, a second group of cells were labeled retrogradely with rhodamine latex beads that were microinjected into the NAc 6-8 d before the brain was used for electrophysiological experiments. Of 17 neurons tested in this group, 13 were electrophysiologically characterized as IB neurons. Eleven of these IB neurons were double-labeled with biocytin (Fig. $14 F, G$ ). The remaining 4 of 17 rhodamine-containing neurons were classified as RS, of which 2 were double-labeled with biocytin and rhodamine microbeads.

\section{Cell morphology}

RS PFC neurons (Fig. 15A)

Biocytin histochemistry was performed on four RS neurons in layers V-VI of the PFC. Typically, these cells had a rounded pyramidal somata. 'I'he proximal dendrites were simple in profile, and their branching was confined to within $\sim 400 \mu \mathrm{m}$ of the soma (Fig. 15A). RS cells had one main axon with several axon collaterals branching off (data not shown). Usually, a single ascending apical dendrite to eminated from the deep-layer somata to the superficial layers I-III. The dendrites typically were thin, possessed few dendritic spines, and lacked elaborate arborizations.

\section{IB PFC neurons (Fig. 15B)}

All nine IB layers V-VI PFC neurons stained with biocytin, were pyramidal cells with a thick, ascending apical dendritic trunk that bifurcated into arborized branches terminating in layers I-II. Proximal dendrites also arose from the deep-layer somatic region and bifurcated profusely. Prominent dendritic spines were present in both the apical dendrites and in the basal proximal dendrites. The projection of the axon could be traced to the white matter in most stained neurons. Collateral axons arose from the main branch and projected perpendicularly and horizontally within layers V-VI.

\section{ROB PFC neurons (Fig. 15C)}

Four ROB PFC neurons stained with biocytin had pyramidal somata located in lower layers V and VI. A thick apical dendrite emerged from the soma and ascended toward the pial surface, where it bifurcated in a tuft in layers II-III and terminated in layers I-II. Oblique branches from the apical dendrite branched off within layers V VI. $\Lambda$ s with the IB neurons, all apical dendritic shafts of these cells were filled with spines. The proximal dendrites originated from the soma and gave off six to eight branches that arborized extensively and created a spherical field of $100 \mu \mathrm{m}$ within the deep layers (Fig.

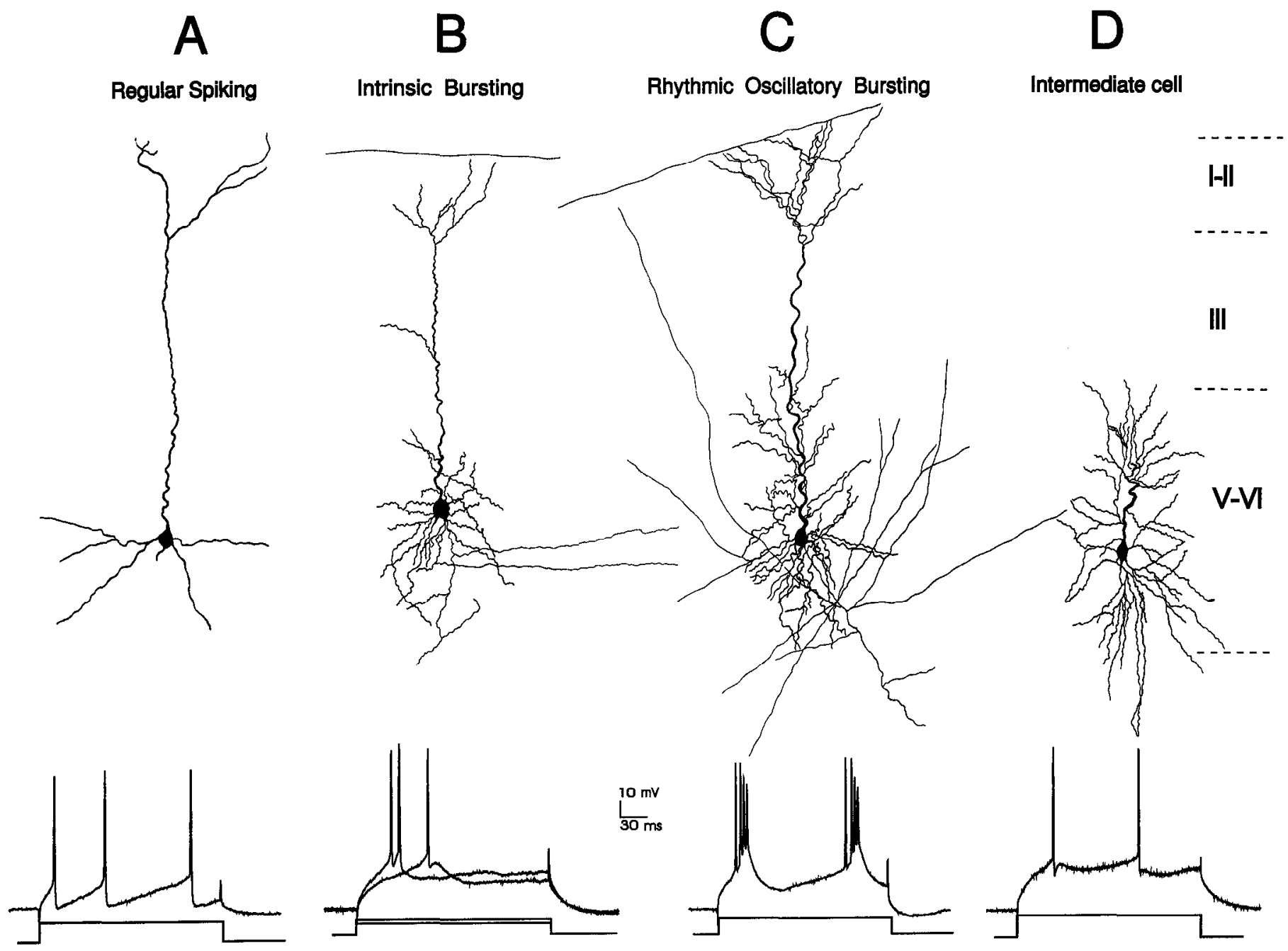

Figure 15. Camera Lucida drawing of the four principal PFC cell types that were stained with biocytin-streptavidin-DAB reactions and their associated electrophysiological responses to intracellular current pulse injections. 
$15 C$ ). Several axon collaterals could be traced projecting within the deep layers or ascending radially to upper layers I-III. All of these dendritic branches were studded with dendritic spines (data not shown).

\section{IM PFC neurons (Fig. 15D)}

Morphologically, the IM cells had comparatively short apical dendrites that did not extend beyond layer III. Extensive arborization of the proximal dendrites was observed within layers V-VI where the elongated soma resided. Dendritic spines were most dense on the proximal dendrites compared with the short apical dendrites (Fig. 15D). Axons of IM cells did not extend out of the layers V-VI.

\section{DISCUSSION}

The four principal pyramidal cell types in layers V-VI of the PFC characterized in this study (see Table 2 for a summary) were: (1) RS cells that fired single spikes, with each spike followed by a prominent postspike AHP that regulated spike frequency adaptation in a spike train. These cells had a single apical dendrite that extended to the superficial layers with few branches in the dendritic arbor; (2) IB cells that fired an initial spike doublet, followed by single spikes with postspike DAPs. These cells typically had an ascending apical dendrite that arborized in superficial layers I-II; (3) ROB cells that fired in repetitive bursts spontaneously or on sustained depolarization. Each burst was followed by a prominent postburst AHP. These cells had extensive apical and proximal dendritic trees and axonal branches that ascended radially to the superficial layers; (4) IM cells that fired single spikes and each of which was followed by a fast AHP, DAP, and mAHP. Morphologically, their dendritic field was confined to layers V-VI.

\section{Firing threshold}

The firing threshold of PFC neurons was determined by the interaction of at least three conductances. First, up to $30 \mathrm{mV}$ from resting $V_{\mathrm{m}}$, a TTX-sensitive, slowly inactivating $\mathrm{Na}^{+}$ current, was activated in RS and IB cells. This current was also responsible for inward rectification in the subthreshold volt- ages range in these cells, and it has a functional role in setting the firing threshold for regenerative fast repetitive spike firing (Schwindt, 1992).

Second, the depolarizing action of this current was counteracted by a 4-AP-sensitive, outwardly rectifying $\mathrm{K}^{+}$current. This $\mathrm{K}^{+}$current was inactive at rest and required prior hyperpolarization to remove the inactivation fully. Although this current was activated in 100-200 msec, it took many seconds to inactivate. This voltage-dependent ionic current resembles the slowly inactivating outward $\mathrm{K}^{+}$current, $\mathrm{I}_{\mathrm{D}}$ or $\mathrm{I}_{\mathrm{KS}}$, and a component of this current is activated selectively by $\mathrm{Na}^{\prime}$ (Storm, 1988; Schwindt et al., 1989; Hammond and Crepel, 1992; Foehring and Surmeier 1993). As $\mathbf{I}_{\mathbf{K S}}$ prevents excessive and sustained membrane depolarization functionally, it could delay spike firing effectively. Because both the $\mathrm{Na}^{+}$and $\mathrm{K}^{+}$currents were slow to inactivate, they may be involved in regulating the general membrane excitability of the neurons over long time courses.

The third current involved in regulating membrane excitability in the subthreshold voltage range is the transient lowthreshold $\mathrm{Ca}^{2+}$ current that mediates the LTS. Although an I.TS can be evoked from resting potential (approximately -75 $\mathrm{mV}$ ), it is more pronounced after prior membrane hyperpolarization. The slowly inactivating $\mathrm{Na}^{+}$currents may provide steady-state inward rectification, the magnitude of which can be enhanced transiently by the rapidly inactivating LTS (Sutor and Zieglgänsberger, 1987). Thus, the transient LTS contributes to subthreshold membrane excitability, especially when the neuron receives prior membrane hyperpolarization (see below).

\section{Subthreshold membrane voltage oscillations}

All four PFC cell types showed subthreshold membrane voltage oscillations in response to a sustained membrane depolarization. All RS and one third of the IB neurons (type 1) oscillated in a narrow-frequency range $(5-12 \mathrm{~Hz})$. Oscillations in this frequency range have been reported previously in the $\mathrm{PFC}$, cingulate, and association and entorhinal cortices (Alonso and Llinas, 1989; Llinas et al., 1991; Alonso and Klink, 1993; Steriade et al., 1993).

Table 2. A summary of the major electrophysiological features of the four cell types in the rat PFC

\begin{tabular}{|c|c|c|c|c|}
\hline & RS & IB & ROB & IM \\
\hline $\begin{array}{l}\text { Subthreshold membrane } \\
\text { oscillation }\end{array}$ & + (Narrow frequency) & $\begin{array}{l}+ \text { (Type } 1, \text { Narrow frequency) } \\
+ \text { (Type } 2, \text { Broad frequency) }\end{array}$ & + (Broad frequency) & + (Broad frequency) \\
\hline Burst firing & - & $+($ Only initial doublet $)$ & + & - \\
\hline Pacemaker-like firing & - & $-($ Type 1$),+($ Type 2$)$ & + & + \\
\hline Postspike DAP & - & + & + & + \\
\hline Postspike AHP & + & + & + & + \\
\hline $\begin{array}{l}\text { Subthreshold TTX-sensitive } \\
\text { depolarizing inward recti- } \\
\text { fication }\end{array}$ & + & + & + & $?$ \\
\hline $\begin{array}{l}\text { 4-AP-sensitive subthreshold } \\
\text { outward rectification }\end{array}$ & + & + & + & $?$ \\
\hline $\begin{array}{l}{\left[\mathrm{Cs}^{+}\right]_{\mathrm{o}} \text {-sensitive hyperpolar- }} \\
\text { ization-activated inward } \\
\text { rectification }\left(I_{\mathrm{h}}\right)\end{array}$ & - & + & + & - \\
\hline Low-threshold $\mathrm{Ca}^{2+}$ spike & - & + & + & $?$ \\
\hline High-threshold $\mathrm{Ca}^{2+}$ spike & + & + & + (Regenerative) & $?$ \\
\hline
\end{tabular}

+, Present; -, absent; ?, not studied. 
These oscillations were abolished by bath application of TTX or intracellular injection of QX314, suggesting that they were mediated by an intrinsic $\mathrm{Na}^{+}$current, most likely the same slowly inactivating $\mathrm{Na}^{+}$current that underlies the subthreshold inward rectification discussed above (Stafstrom et al., 1982, 1985; Alonso and Llinas, 1989; Alonso and Klink, 1993; Klink and Alonso, 1993; Taylor, 1993). In addition, depolarizing and hyperpolarizing synaptic inputs may have provided an extrinsic regulation of membrane oscillations in vivo when the entire cortical network was intact (Steriade et al., 1993; Cowan and Wilson, 1994).

The majority of the IB (type 2) and ROB and all of the IM cells exhibited a sinusoidal rhythmic pacemaker-like firing with increased frequency $(1-30 \mathrm{~Hz})$ on sustained membrane depolarization. These two different oscillation patterns may represent different modes of signal transmission by these PFC cells under different behavioral conditions.

Neuronal membrane oscillations may synchronize functionally the activity of a given network of neurons, thus ensuring that neuronal groups that resonate at the same frequency will fire in synchrony. A common mode of oscillation shared by cortical neurons from adjacent columns (often connected by horizontally projecting interneurons) could constitute a synchronizing mechanism through which the activity patterns of multiple inputs are coordinated (Alonso and Klink, 1993; Lampl and Yarom, 1993; Singer, 1993). In the PFC, membrane oscillations transfered through the tangentially projecting axons of IB and ROB neurons may synchronize firing at sites both proximal and distal to the site of generation.

\section{Low-threshold and high-threshold $\mathrm{Ca}^{2+}$ conductances}

Prominent low- and high-voltage-activated $\mathrm{Ca}^{2+}$ currents govern the bursting behavior of the IB and ROB PFC neurons. As activation of the LTS requires removal of inactivation by voltage excursions from about -55 to more than -70 to $-100 \mathrm{mV}$ for at least 50-100 msec, the LTS may be triggered physiologically as a rebound response to a powerful long-duration IPSP mediated by $\mathrm{GABA}_{\mathrm{B}}$ receptors (Connors et al., 1988). Once activated, the LTS causes a membrane depolarization that may elicit the voltagedependent oscillations discussed above. The occurrence of this event is dependent on factors such as the length of time the membrane potential has been hyperpolarized and the time since the last LTS was triggered (McCormick and Feeser, 1990; Jahnsen and Llinas, 1984).

After blockade of the $\mathrm{Na}^{+}$and $\mathrm{K}^{+}$channels by TTX and TEA, respectively, short current pulses triggered large-amplitude and long-duration $\mathrm{Ca}^{2+}-\mathrm{HTS}$ from $-40 \mathrm{mV}$. Unique to the IB and ROB ncurons was their ability to elicite regenerative HTS once a single HTS was triggered (Amitai et al., 1993). Voltage-dependent activation of the dendritic HTS by incoming synaptic signals or by back-propagated of action potentials from the soma may, in turn, amplify the dendritic synaptic signals (Miller et al., 1985; Shepherd et al., 1985; Bernander et al., 1994; Mel, 1994; Stuart and Sakmann, 1994; Magee and Johnston, 1995). In addition, local HTS-mediated dendritic depolarizations may relieve the voltagedependent $\mathrm{Mg}^{2+}$ block of the NMDA receptor channel complex briefly, resulting in changes in synaptic efficacy (Hirsch and Crepel, 1990; Sah and Nicoll, 1991).

Recent evidence from studies using $\mathrm{Ca}^{2+}$ imaging or dendritic recordings suggests that there are compartmentalized dendritic locations that generate the HTS (Yuste et al., 1994). The extensively ramified apical denditic arbor of IB and ROB neurons, with dendritic spines, may serve as the key receptive zones where projections from association cortices terminate (Pandya and Yeterian, 1985; Herkenham, 1986; Amitai et al., 1993; Reuveni et al., 1993; Yuste et al., 1994). Given its proposed functions and site of generation, the dendritic HTS may regulate input-output characteristics of PFC neurons (see companion paper in this issue).

\section{Anomalous rectification in the hyperpolarized voltage range}

Both IB and ROB neurons show hyperpolarization-activated inward rectification. A weak time-dependent, external cesiumsensitive inward rectification was associated with IB neurons. In contrast, a prominent transient sag mediated by an external cesium-sensitive, hyperpolarization-activated, time-dependent inward rectification represents one of the major features that identifies the ROB neurons in the PFC. This transient sag is likely to be mediated by a voltage- and time-dependent hyperpolarizationactivated mixed cationic current called $I_{\mathrm{h}}$. This current slowly repolarizes the neuron after prolonged hyperpolarization, e.g., by a $\mathrm{GABA}_{\mathrm{B}}$ receptor-mediated IPSP or a postburst AHP (Schwindt, et al., 1988; McCormick and Pape, 1990; Kamondi and Reiner; 1991). At the end of the repolarization by $I_{\mathrm{h}}$, a rebound LTSmediated spike burst can be triggered. In this manner, the interaction of $I_{\mathrm{h}}$ and the LTS may underly the unique bursting behavior of ROB neurons in the PFC (McCormick and Pape, 1990; Foehring and Waters, 1991).

\section{The DAP and AHP}

IB, ROB, and IM cells all possessed a postspike DAP. In IB cells, summation of the postspike DAPs from two single spikes forms a burst of spike doublet. In ROB neurons, the bursting complex also was derived from a DAP that followed a single action potential. Whereas the DAP usually is necessary for the neuron to fire in spike bursts, IM cells that possessed a DAP never fired in bursts. Thus, the role of the DAP in these neurons is unclear.

The ionic basis for the postspike DAPs differs widely in various central neurons. In PFC neurons, $\mathrm{Ca}^{2+}$ entry played a critical role in the electrogenesis of DAPs, because removal of $\left[\mathrm{Ca}^{2+}\right]_{0}$ markedly attenuated or abolished the DAPs. In anterior cingulate neurons, there is evidence that the postspike DAP is mediated by a $\mathrm{Ca}^{2+}$-activated outward $\mathrm{Cl}^{-}$current (Higashi et al., 1993).

RS neurons were the only cells that did not possess DAPs. In contrast, these cells exhibited a prominent postspike AHP that most likely was mediated by a $\mathrm{Ca}^{2+}$-activated $\mathrm{K}^{+}$current (Schwindt et al., 1988, 1992). These postspike AHPs determined largely the degree of spike frequency adaptation during repetitive firing. In ROB neurons, a postburst AHP followed each burst. Both burst firing and postburst AHPs were dependent on extracellular $\mathrm{Ca}^{2+}$ entry, because they were abolished in $\mathrm{Ca}^{2+}$-free media. Together, these data suggest a critical role for extracellular $\mathrm{Ca}^{2+}$ in triggering bursts and DAPs and in activation of $\mathrm{Ca}^{2+}$ dependent $\mathrm{K}^{+}$currents that underlie postburst AHPs (Schwindt et al., 1988).

\section{Antidromic responses and rhodamine microbeads/biocytin double-labeling of PFC $\rightarrow$ NAc neurons}

Antidromic responses were evoked in presumed $\mathrm{PFC} \rightarrow \mathrm{NAc}$ neurons in $16 \%$ of all recorded PFC neurons after NAc stimulation. The majority were characterized electrophysiologically as IB neurons. However, this is not surprising given that most of the deep layers V-VI PFC neurons examined were classified as IB neurons. Failure to identify a greater number of PFC neurons that responded antidromically to NAc stimulation may be attributed to 
the anatomical organization of this projection (Gorelova et al., 1995). In our anterograde tracing study in which we examined the entire course of projection of this pathway, we found that corticostriatal neurons project from the PFC topographically and diffusely to the NAc. After entering the NAc, PFC axons ramify profusely. The tortuous nature of this projection and its diffuse terminations precluded preservation of this pathway in its entirety in the slice preparation. This may explain why few PFC cells responded to antidromic stimulation of the NAc.

The rhodamine bead/biocytin double-labeled neurons found in this study also confirmed that the $\mathrm{PFC} \rightarrow \mathrm{NAc}$ neurons largely belong to the IB class of pyramidal neurons. Furthermore, the majority of the retrogradely labeled PFC neurons after NAC injection of the tracer were distributed in deep layers V-VI, thus confirming previous neuroanatomical findings (Sesack et al., 1989; Berendse et al., 1992; Brog et al., 1993).

\section{Morphology of the four principal cell types}

In this study, the most frequently encountered PFC cell type in layers V-VI was IB. As with ROB cells, these neurons had a single, thick main ascending apical dendrite. It is interesting that both these two classes of pyramidal neurons exhibited the capacity to fire in bursts. Bursting cells with thick ascending apical dendrites have also been found in the deep layers of rat somatosensory and visual cortices (Chagnac-Amitai et al., 1990; Mason and Larkman 1990). I Iowever, Kawaguchi (1993) reported that none of the two kinds of pyramidal neurons found in the rat medial agranular frontal cortex exhibited burst firing. The use of patchclamp recording from cortical tissues of immature rats $(16-22 \mathrm{~d})$ at room temperature $\left(26-27^{\circ} \mathrm{C}\right)$ might have contributed to the discrepancy between the results of that study and the present study.

A key feature that distinguished IB and ROB neurons morphologically was the distribution of proximal or basal dendrites. Because of the larger area encompassed by the basal dendrites of the ROB neurons, which often extend throughout layers III-VI, there was a greater possibility for integration of synaptic inputs. In addition, the extensive axonal arborizations and radially ascending collaterals in these neurons may allow transmission of input signals back to neurons localized in the more superficial layers. In contrast, the basal proximal dendrites of the IB neurons were confined within layers V-VI. Thus, this type of neuron may be influenced only by inputs to deep layers V-VI, from regions such as the thalamus.

In contrast to the IB and ROB neurons, the nonbursting RS and IM cells had a comparatively simpler morphology. RS PFC neurons had a single ascending apical dendrite that lacked extensive bifurcations. The basal proximal dendritic field of RS cells also was restricted and limited to deep layers V-VI. Therefore, like IB cells, RS cells may be influenced by a restricted range of inputs.

IM cells may have a similar appearance to cortical interneurons, because of their lack of ascending apical dendrites. However, unlike cortical interneurons, the IM cells did not fire thin repetitive spikes lacking spike accomodation (McCormick et al., 1985; Kawaguchi, 1993). The IM PFC cells resemble pyramidal cells recorded in deep layers V-VI of the rat somatosensory, motor, and visual corticies, which also have short, thick apical dendrites terminating in layer III (Katz, 1987; van Brederode and Snyder, 1992; Kang and Kayano, 1994). The IM cells of the PFC are unlikely to be interneurons but rather pyramidal cells with a localized field of influence within a small area of the PFC.

\section{Functional considerations}

Data from many experiments in which single-unit activity was recorded in the PFC of freely moving animals subjected to specific behavioral paradigms suggest that the PFC is involved in short-term memory related to the preparation of motor sets (Fuster 1995). Most notably, some PFC neurons in the primate fire continuously throughout the delay period of a delayed response task, and this neuronal activity may serve to "hold" information temporarily (GoldmanRakic, 1995a,b). Other "anticipatory" units discharge before the onset of a conditioned stimulus, before the delivery of reward, or before a specific response (Niki and Watanabe, 1979; Yamatani et al., 1990). Fuster (1995) suggests that purposeful motor behavior is organized temporally by the PFC via the coordinated activity of the prospective function of preparatory motor set and a retrospective function of short-term memory.

Neurons in the prelimbic cortex of the rat also show increased firing rates before the execution of a correct response during a delayed-response task (Batuev et al., 1990; Chang et al., 1994). Recently, we have demonstrated that transient lidocaine-induced lesions of this area of the rat PFC lead to disorganized and inaccurate foraging behavior on a delayed, but not continuous, foraging task on a radial arm maze (Seamans et al., 1995). Hence, like the dorsolateral PFC in the primate, the prelimbic cortex of the rat plays an important role in the ability to use short-term memory to prepare a series of organized responses.

Much of what we understand about the intrinsic membrane properties of neocortical neurons has been used to explain changes in membrane excitability that ultimately lead to the regulation of firing activity (Schwindt, 1992). The various intrinsic membrane properties described in the present paper may influence neuronal excitability in the mammlian PFC. For example, the ability of $\mathrm{PFC}$ neurons to sustain repetitive firing throughout a delay period may depend on the complex interplay of the slowly inactivating $\mathrm{Na}^{+}$and $\mathrm{K}^{+}$currents that regulate firing threshold and the $\mathrm{Ca}^{2+}$-activated $\mathrm{K}^{+}$currents that regulate interspike intervals. The membrane oscillations exhibited by layers V-VI PFC neurons may synchronize the output of large groups of PFC neurons, thus allowing a coherent signal to be transmitted to subcortical areas such as the NAc for response initiation. Finally, the HTS observed in PFC neurons may play a role in regulating the influence of inputs from regions such as the posterior parietal cortex or thalamus. This may be of particular importance given that the PFC interacts reciprocally with these areas during the performance of a delayed-response task (Goldman-Rakic and Chaffe, 1994; Goldman-Rakic, 1995a,b). It is anticipated that any neurotransmitter-neuromodulator that affects these currents potentially could have a large influence on PFC neuronal activity and performance of tasks that depend on this region. The findings from this study provide the basis for studying the modulatory actions of the major ascending transmitter/neuromodulator systems on the intrinsic membrane properties of PFC neurons. We have undertaken the study of the effects of dopamine on some of these conductances in PFC neurons (see the companion paper, this issue).

\section{REFERENCES}

Alonso A, Klink R (1993) Differential electroresponsiveness of stellate and pyramidal-like cells of medial entorhinal cortex layer II. J Neurophysiol 70:128-143.

Alonso A, Llinas RR (1989) Subthreshold $\mathrm{Na}^{+}$-dependent theta-like rhythmicity in stellate cells of entorhinal cortex layer II. Nature 342:175-177. 
Amitai Y, Friedman A, Connors BW, Gutnick MJ (1993) Regenerative activity in apical dendrites of pyramidal cells in neocortex. Cereb Cortex $3: 26-38$.

Batuev AS, Kurina NP, Shutov AP (1990) Unit activity of the medial wall of the frontal cortex during delayed performance in rats. Behav Brain Res 41:95-102.

Berendse IIW, Galis-De Graaf Y, Groenewegen HJ (1992) Topographical organization and relationship with ventral striatal compartments of prefrontal corticostriatal projections in the rat. J Comp Neurol 316:314-347.

Bernander Ö, Koch C, Douglas R (1994) Amplification and linearization of distal synaptic input to cortical pyramidal cells. J Neurophysiol 72:2743-2753.

Brog JS, Salyapongse A, Deutch AY, Zahm DS (1993) The patterns of afferent innervation of the core and shell in the "accumbens" part of the rat ventral striatum: immunohistochemical detection of retrogradely transported Fluoro-Gold. J Comp Neurol 338:255-278.

Chagnac-Amital Y, Luhnam HJ, Prince DA (1990) Burst generating and regular spiking layer 5 pyramidal neurons of rat neocortex have different morphological features. J Comp Neurol 296:598-613.

Chang JY, Laubach MG, Kirillov A, Woodward DJ (1994) Neuronal activities in basal ganglia and frontal cortex during delayed match to sample task in freely moving rats. Soc Neurosci Abstr 20:781.

Condé F, Marie-Lepoivre E, Audinat E, Crépel F (1995) Afferent connections of the medial frontal cortex of the rat. II. Cortical and subcortical afferents. J Comp Neurol 352:567-593.

Connors BW, Gutnick MJ (1990) Intrinsic firing patterns of diverse neocortical neurons. Trends Neurosci 13:99-104.

Connors BW, Gutnick MJ, Prince DA (1982) Electrophysiological properties of neocortical neurons in vitro. J Neurophysiol 48:1302-1320.

Connors BW, Malenka RC, Silva LR (1988) Two inhibitory postsynaptic potentials, and $\mathrm{GABA}_{\mathrm{A}}$ and $\mathrm{GABA}_{\mathrm{B}}$ receptor-mediated responses in neocortex of rat and cat. J Physiol (Lond) 406:443-468.

Cowan RL, Wilson CJ (1994) Spontaneous firing patterns and axonal projections of single corticostriatal neurons in the rat medial agranular cortex. J Neurophysiol 71:17-32.

Franz P., Galvan M, Constanti $\Lambda$ (1986) Calcium dependent activity pattern and the associated inward calcium currents in guinea pig neocortical neurons in vitro. Brain Res 366:262-267.

Foehring RC, Surmeier DJ (1993) Voltage-gated potassium currents in acutely dissociated rat cortical neurons. J Neurophysiol 70:51-63.

Foehring RC, Waters RS (1991) Contributions of low-threshold calcium current and anomalous rectifier (Ih) to slow depolarizations underlying burst firing in human neocortical neurons in vitro. Neurosci Lett 124:17-21.

Friedman A, Gutnick MJ (1989) Intracellular calcium and control of bursting generation in neurons of guinea-pig neocortex in vitro. Eur $\mathrm{J}$ Ncurosei 1:374-381.

Fuster JM (1995) Memory in the cerebral cortex: an empirical approach to neural networks in the human and nonhuman primate. Cambridge: MIT.

Goldman-Rakic PS (1995a) Toward a circuit model of working memory and the guidance of voluntary motor action. In: Models of information processing in the basal ganglia. (Houk JC, Dacis JC, Beiser DG, eds) Chap 7, pp 131-148. Cambridge: Bradford Book, MIT.

Goldman-Rakic PS (1995b) Cellular basis of working memory. Neuron 14:477-485.

Goldman-Rakic PS, Chaffe M (1994) Feedback processing in prefrontoparietal circuits during memory-guided saccades. Soc Neurosci Abstr 20:808.

Gorelova N, Yang CR, Seamans JK (1994) Projection of the prefrontal cortex-nucleus accumbens neurons. Soc Neurosci Abstr 20:529.

Gorelova N, Yang CR, Seamans JK (1995) Soma-dendritic dopaminergic (DA) modulation of activated prefrontal cortex $\rightarrow$ nucleus accumbens $(\mathrm{PFC} \rightarrow \mathrm{NAc}$ ) neurons in vitro. Soc Neurosci Abstr 21:1904.

Groenewegen HJ (1988) Organization of the afferent connections of the mediodorsal thalamic nucleus in the rat, related to the mediodorsalprefrontal topography. Neuroscience 24:379-431.

Groenewegen HJ, Berendse HW, Wolters JG, Lohman AHM (1990) The andomical relationship of the prefrontal cortex with the striatopallidal system, the thalamus and the amygdala: evidence for a parallel organization. Prog Brain Res 85:95-118.

Guthrie PB, Segal M, Kater SB (1991) Independent regulation of calcium revealed by imaging dendritic spines. Nature 354:76-80.
Hammond C, Crépel F (1992) Evidence for a slowly inactivating $\mathrm{K}^{+}$ current in prefrontal cortical cells. Eur J Neurosci 4:1087-1092.

Herkenham M (1986) New perspectives on the organization and evolution of non-specific thalamocortical projections. In: Cerebral cortex, Vol 5 (Jones EG, Peters A, eds) pp 403-445. New York: Plenum.

Higashi H, Tanakam E, Inokuchi H, Nishi S (1993) Ionic mechanisms underlying the depolarizing and hypcrpolarizing aftcrpotentials of single spike in guinea-pig cingulate cortical neurons. Neuroscience 55:129-138.

Hirsch JC, Crepel F (1990) Use-dependent changes in synaptic efficacy in rat prefrontal neurons in vitro. J Physiol (Lond) 427:31-49.

Jahnsen H, Llinas R (1984) Ionic basis for the electroresponsiveness and oscillatory properties of guinea-pig thalamic neurones in vitro. J Physiol (Lond) 349:227-247.

Kamondi A, Reiner PB (1991) Hyperpolarization-activated inward current in histaminergic tuberomammillary neurons of the rat hypothalamus. J Neurophysiol (Lond) 66:1902-1911.

Kang Y, Kayano F (1994) Electrophysiological and morphological char acteristics of layers VI pyramidal cells in the cat motor cortex. J Neurophysiol 72:578-591.

Kalz LC (1987) Loül circuitry of identified projection neurons in cat visual cortex brain slices. J Neurosci 7:1223-1249.

Kawaguchi Y (1993) Groupings of nonpyramidal and pyramidal cells with specific physiological and morphological characteristics in rat frontal cortex. J Neurophysiol 69:416-431.

Klink R, Alonso A (1993) Ionic mechanisms for the subthreshold oscillations and differential electroresponsiveness of medial entorhinal cortex layer II neurons. J Neurophysiol 70:144-157.

Kolb B (1984) Functions of the frontal cortex of the rat: a comparative review. Brain Res Rev 8:65-98.

Lampl I, Yarom Y (1993) Subthreshold oscillations of the membrane potential: a functional synchronizing and timing device. J Neurophysiol 70:2181-2186.

Larkman A, Mason A (1990) Correlations between morphology and electrophysiology of pyramidal neurons in slices of rat visual cortex. II Establishment of cell classes. J Neurosci 10:1407-1414.

Llinas R (1986) Intrinsic electrophysiological properties of mammalian neurons: insights into the central nervous system functions. Science $242: 1654-1664$.

Llinas R, Grace AA, Yarom Y (1991) In vitro neurons in mammalian cortical layer 4 exhibit intrinsic oscillatory activity in the $10-$ to $50-\mathrm{Hz}$ frequency range. Proc Natl Acad Sci USA 88:897-901.

Lipski $J$ (1981) Antidromic activation of neurons as an analytical tool in the study of the central nervous system. J Neurosci Methods 4:1981-2032.

Magee JC, Johnston D (1995) Synaptic activation of voltage-gated channels in the dendrites of hippocampal pyramidal neurons. Science 268:301-304.

Mason A, Larkman A (1990) Correlations between morphology and electrophysiology of pyramidal neurons in slices of rat visual cortex. II. Electrophysiology. J Neurosci 10:1415-1428.

McCormick DA (1992) Neurotransmitter actions in the thalamus and cerebral cortex and their role in neuromodulation of thalamocortical activity. Prog Neurobiol 39:337-388.

McCormick DA, Pape H-C (1990) Properties of a hyperpolarizationactivated cation current and its role in rhythmic oscillation in thalamic relay neurons. J Physiol (Lond) 431:291-318.

McCormick DA, Feeser HR (1990) Functional implications of burst firing and single spike activity in lateral geniculate relay neurons. Neuroscience 39:103-113.

McCormick DA, Connors BW, Lighthall JW, Prince DA (1985) Comparative electrophysiology of pyramidal and sparsely spiny stellate neurons of the neocortex. J Neurophysiol 54:782-806.

Mel BW (1994) Information processing in dendritic trees. Neural Comp 6:1031-1085.

Miller JP, Rall W, Rinzel J (1985) Synaptic amplification by active membrane in dendritic spines. Brain Res 325:325-330.

Mogenson GJ, Brudzynski S, Wu M, Yang CR, Yim CY From motivation to action: a review of dopaminergic regulation of limbic $\rightarrow$ nucleus accumbens $\rightarrow$ ventral pallidum $\rightarrow$ pedunculopontine nucleus circuitries involved in limbic-motor integration. In: The mesolimbic motor circuit and its role in neuropsychiatric disorders (Kalivas P, Barnes C, eds), pp 193-236, Boca Raton: CRC.

Müller W, Connors JA (1991) Dendritic spines as individual neuronal compartments for synaptic $\mathrm{Ca}^{2+}$ responses. Nature 354:73-76. 
Niki H, Watanabe M (1979) Prefrontal and cingulate unit activity during timing behavior in the monkey. Brain Res 171:213-224.

Pandya DN, Yeterian EH (1985) Architecture and connections of cortical association areas. In: Cerebral cortex, Vol 4 (Peters A, Jones EG, eds), pp 3-61. New York: Plenum.

Reuveni I, Friedman A, Amitai Y, Gutnick MJ (1993) Stepwise repolarization from $\mathrm{Ca}^{2+}$ plateaus in neocortical pyramidal cells: evidence for nonhomogeneous distribution of HVA $\mathrm{Ca}^{2+}$ channels in dendrites. J Neurosci 13:4609-4621.

Sah P, Nicoll RA (1991) Mechanisms underlying potentiation of synaptic transmission in rat anterior cingulate cortex in vitro. J Physiol (Lond) 433:615-630.

Schwindt PC (1992) Ionic currents governing input-output relations of Betz cells. In: Singel neuron computation (McKenna T, Davis J, Zornetzer SF, eds), pp 235-258. New York: Academic.

Schwindt PC, Spain WJ, Foehring RC, Stafstrom CE, Chubb MC, Crill WE (1988) Multiple potassium conductances and their functions in neurons from cat sensorimotor cortex in vitro. J Neurophysiol 59:424-449.

Schwindt PC, Spain WJ, Crill WE (1992) Calcium-dependent potassium currents in neurons from cat sensorimotor cortex. J Neurophysiol 67:216-226.

Schwindt PC, Spain WJ, Crill WE (1989) Long lasting reduction of cxcitability by a sodium-dependent potassium current in eat nepcortical neurons. J Neurophysiol 61:233-244.

Seamans JK, Phillips AG (1994) Selective memory impairments produced by transient lidocaine-induced lesions of the nucleus accumbens in rats. Behav Neurosci 108:456-468.

Seamans JK, Floresco SB, Phillips AG (1995) Functional differences between the prelimbic and anterior cingulate regions of the rat prefrontal cortex. Behav Neurosci 109:1-11.

Sesack SR, Deutch AY, Roth RH, Bunney BS (1989) Topographical organization of the efferent projections of the medial prefrontal cortex in the rat: an anterograde tract-tracing study with Phaseolus vulgaris leucoagglutinin. J Comp Neurol 290:213-242.

Shepherd GM, Brayton RK, Miller JP, Segev I, Rinzel J, Rall W (1985) Signal enhancement in distal cortical dendrites by means of interactions between active dendritic spines. Proc Natl Acad Sci USA 82:2192-2195.

Silva LR, Amital Y, Connors BW (1991) Intrinsic oscillations of neocortex generated by layer 5 pyramidal neurons. Science 251:432-435.

Singer W (1993) Synchronization of cortical activity and its putative role in information processing and learning. Annu Rev Physiol $55: 349-374$.
Stafstrom CE, Schwindt PC, Crill WE (1982) Negative slope conductance due to a persistent subthreshold sodium current in cat neocortical neurons in vitro. Brain Res 236:221-226.

Stafstrom CE, Schwindt PC, Chubb MC, Crill WE (1985) Properties of persistent sodium conductance \& calcium conductance of layers $\mathrm{V}$ neurons from cat sensorimotor cortex in vitro. J Neurophysiol 53:153-170.

Steriade M, Nunez A, Amzica F (1993) A novel slow ( $<1 \mathrm{~Hz}$ ) oscillation of neocortical neurons in vivo: depolarizing and hyperpolarizing components. J Neurosci 13:3252-3265.

Storm JF (1988) Temporal integration by a slowly inactivating $\mathrm{K}^{+}$current in hippocampal neurons. Nature 336:379-381.

Stuart GJ, Sakmann B (1994) Active propagation of somatic action potentials into neocortical pyramidal cell dendrites. Nature 367:69-72.

Sutor B, 7ieglgansherger W (1987) A low-voltage activated, transient calcium current is responsible for the time-dependent depolarizing inward rectification of rat neocortical neurons in vitro. Pflueger's Arch 410:102-111.

Taylor CP (1993) $\mathrm{Na}^{+}$currents that fail to inactivate. Trends Neurosci $16: 455-460$.

Thesleff S (1980) Aminopyridine and synaptic transmission. Neuroscience 5:1413-1419.

Uylings HBM, van Eden CG (1990) Qualitative and quantitative comparison of the prefrontal cortex in rat and in primates, including humans. Prog Brain Res 85:31-61.

van Brederode JFM, Snyder GL (1992) A comparison of the electrophysiological properties of morphologically identified cells in layer $5 B$ and 6 of the rat neocortex. Neuroscience 50:315-337.

Yamatani K, Ono T, Nishijo H, Takaku A (1990) Activily antd distribution of learning-related neurons in monkey (macaca fuscata) prefrontal cortex. Behav Neurosci 104:503-531.

Yang CR, Seamans JK (1994) Actions of dopamine on prefrontal cortex pyramidal neurons in brain slices that preserve the PFC-nucleus accumbens projection. Soc Neurosci Abstr 20:529.

Yang CR, Seamans JK (1996) Dopamine D1 receptor actions in layers V-VI rat prefrontal cortex neurons in vitro: modulation of dendriticsomatic signal integration. J Neurosci 16:1922-1935.

Ye HJ, Akaike N (1993) Calcium currents in pyramidal neurons acutely dissociated from the rat frontal cortex: a study by the nystatin perforated patch techniques. Brain Res 606:111-117.

Yuste R, Gutnick M, Saar D, Delaney KR, Tank DW (1994) $\mathrm{Ca}^{2+}$ accumulations in dendrites of neocortical pyramidal neurons: an apical band and evidence for two functional compartments. Neuron 13:23-43. 